\title{
Gladius materialis ecclesiae
}

\author{
Von
}

\section{Andreas Kosuch}

The studies of Alfons M. Stickler concerning the term gladius materialis in canonistic sources of the $11^{\text {th }}-13^{\text {th }}$ centuries resulted in the distinction of state authority and coercive power of the church in temporal affairs (gladius materialis ecclesiae). According to Stickler, only by this distinction it is possible to explain otherwise inconsistent statements of e. g. Huguccio and other canonists concerning the gladius materialis. Stickler can't supply evidence for an explicitly conceptualized doctrine of the gladius materialis ecclesiae, however in the ecclesio-political writings of Francisco de Vitoria at the beginning of the $16^{\text {th }}$ century the gladius materialis ecclesiae indeed became evident as a symbol of the coercive power of the church in temporal affairs apart from the state authority. But in the doctrine of the papal potestas indirecta, the prevalent theory for church-state relations in the early modern age, the jusnaturalistic state authority and the Christ-based coercive power of the church in temporal affairs was again subsumed under the term gladius materialis in context of the two-sword allegory, and both swords (gladius spiritualis and gladius materialis) were attributed to the pope. In this interpretation the medieval allegory of the two swords was present in canonistic coursebooks up to the time of Vatican II., but also stayed a main reason for misunderstandings and difficulties of interpretation.

Die Forschungen von Alfons M. Stickler zur Verwendung des Begriffs gladius materialis in kanonistischen Quellen des 11.-13. Jahrhunderts forderten im Ergebnis die Unterscheidung zwischen der rein weltlichen (Staats-)Gewalt und der materiell-zeitlichen Zwangsgewalt der Kirche (gladius materialis ecclesiae). Nur durch eine derartige Differenzierung ließen sich nach Ansicht Sticklers ansonsten widersprüchliche Aussagen etwa bei Huguccio und anderen Kanonisten erklären. Den Nachweis für eine in der mittelalterlichen Kanonistik explizit konzipierte Lehre vom gladius materialis ecclesiae kann Stickler letztlich nicht erbringen, doch zu Beginn des 16. Jahrhunderts tritt in den kirchenpolitischen Schriften des Salmantiner Theologen Francisco de Vitoria der gladius materialis ecclesiae tatsächlich als Symbol für eine neben der staatlichen Gewalt existierende kircheneigene materielle Zwangsgewalt deutlich hervor. In der die Neuzeit maßgeblich bestimmenden Lehre von der potestas indirecta allerdings wurden die naturrechtliche Staatsgewalt und die auf Christus basierende materielle Zwangsgewalt der Kirche - obgleich auch hier theoretisch voneinander geschieden - erneut im Kontext der Zwei-Schwerter-Lehre unter dem einen Begriff des gladius materialis subsumiert und letztlich beide Schwerter (gladius spiritualis und gladius materialis) dem Papst zugesprochen. In dieser Interpretation blieb die mittelalterliche Zwei-Schwerter-Lehre bis in die Zeit des Vaticanum II. in kanonistischen Lehrbüchern präsent, sie blieb jedoch auch ein wesentlicher Grund für Interpretationsschwierigkeiten und Missverständnisse. 


\section{Vorbemerkung}

Eine der umstrittensten Bestimmungen des Zweiten Vatikanischen Konzils ist das Dekret Dignitatis humanae, in dem sich die katholische Kirche zur Religionsfreiheit bekannte und damit zugleich die Abkehr von einer Kirche verkündete, die „ihre Wahrheit und ihre pastorale Aufgabe mit den Mitteln weltlicher Gewalt zu behaupten und durchzusetzen versucht“"1). Mit Dignitatis humanae vollzog die Kirche einen Bruch mit einer über 1000-jährigen Tradition, wonach der Staat als brachium saeculare im Namen und auf Geheiß der Kirche materiell-zeitliche Strafen zu vollstrecken habe²). Theologen urteilen bisweilen unterschiedlich darüber, ob die Kirche mit diesem Verzicht auf eine ihr zustehende materielle Zwangsgewalt das depositum fidei, den inneren Glaubenskern der katholischen Lehre, verletzt oder aber nur historischen Ballast abgeworfen habe, den sie sich in der nachkonstantinischen Epoche sukzessive aufgeladen hatte und der sich im Hochmittelalter schließlich in kanonistischen Rechtstraditionen und den dazugehörigen Formeln wie der Zwei-Schwerter-Lehre verfestigte ${ }^{3}$ ). Auch wenn der kirchliche Anspruch auf eine materielle Zwangsgewalt eine lange Tradition besaß, setzen neuere Forschungen zum Thema für gewöhnlich erst mit der Etablierung des Ius Publicum Ecclesiasticum als eigenständige kirchenrechtliche Teildisziplin im späten 18. Jahrhundert ein, als die katholische Kirche mit Verweis auf ihre Eigenschaft als societas perfecta ihren umfassenden Anspruch auf eine eigene Strafgewalt rechtlich ausformulierte und dabei neben der ihr zustehenden geistlichen auch eine eigene materielle Zwangsgewalt für sich reklamierte. Der Grundgedanke war, dass der Kirche als eigenständiger, von staatskirchlichem Einfluss unabhängiger societas perfecta alle Mittel zur Verfügung stehen müssten, um die ihr eigenen geistlich-religiösen Ziele auch erreichen zu können, und dazu gehöre auch die Möglichkeit, materielle Zwangsmittel anwenden und durchsetzen zu können. Während in der Literatur Verweise auf die frühneuzeitlichen Wurzeln der kirchlichen societas perfecta-Lehre nicht fehlen, werden hoch- und spätmittelalterliche Vorstellungen über eine

1) So Martin Rhonheimer, Religionsfreiheit - Bruch mit der Tradition?, in: Die Neue Ordnung 65 (2011) 244-261, S. 258.

2) Vgl. Ernst-Wolfgang Böckenförde, Religionsfreiheit, Die Kirche in der modernen Welt, Freiburg 1990, S. 59ff. Zum brachium saeculare vgl. René Laprat, Art. „bras séculier“, Dictionnaire de droit canonique, Bd. 2 Paris 1937, Sp. 981-1060; Arnold Angenendt, Sakralherrschaft und Religionsfrevel, Oder: Wer hat das brachium saeculare erfunden?, in: F. - R. Erkens (Hg.), Das frühmittelalterliche Königtum, Ideelle und religiöse Grundlagen, Berlin 2005, S. 376-406.

3) Vgl. Rhonheimer, Religionsfreiheit (oben Anm. 1) 257. 
materielle Zwangsgewalt der Kirche gemeinhin unter dem Vorzeichen der Hierokratie gelesen, wonach dem Papst als Inhaber der plenitudo potestatis ohnehin eine potestas directa in temporalibus zugestanden wurde, was in späterer Zeit - cum grano salis - als theologische wie kanonistische Fehlentwicklung angesehen wurde und daher nicht mehr als brauchbare Grundlage für einen kirchlichen Anspruch auf materielle Zwangsgewalt dienen konn$\mathrm{te}^{4}$ ). Der Kuttner-Schüler und spätere Kurienkardinal Alfons Maria Stickler hatte jedoch in der Mitte des 20. Jahrhunderts in zahlreichen Einzelstudien eine seinerzeit vielbeachtete und noch heute in kirchengeschichtlichen und theologischen Handbüchern und Fachlexika anzutreffende ${ }^{5}$ ) Interpretation der mittelalterlichen Zwei-Schwerter-Lehre vorgelegt, der zufolge führende Kanonisten und Theologen bis ins frühe 13. Jahrhundert und zum Teil darüber hinaus für die Kirche eine eigene und umfassende materielle Zwangsgewalt beansprucht hätten, ohne den Irrweg der Hierokratie zu beschreiten.

\section{Alfons M. Stickler und die Theorie vom gladius materialis ecclesiae}

Ausgangspunkt der Überlegungen Sticklers waren die großen Konflikte zwischen den beiden Universalgewalten im 11. und 12. Jahrhundert, in denen das harmonische Gewaltenverständnis des frühen Mittelalters, wonach imperium und sacerdotium gleichsam „im Austausch ihrer Vorrechte“汭) zum Wohle der ecclesia universalis einander beistehen sollten, auf eine harte Probe gestellt wurde. In Zeiten, in denen das imperium seiner Verpflichtung zum bewaffneten Schutz der Kirche nicht nachkommen wollte oder sich gar gegen das sacerdotium wandte, musste sich die grundsätzliche Frage stellen, „ob die Kirche selbst eine ihr gehörige, also eine rein kirchliche materielle Zwangsge-

$\left.{ }^{4}\right)$ Es mangelt freilich in der Forschung nicht an Versuchen, die in der Neuzeit vorherrschende Lehre der päpstlichen potestas indirecta ins Hochmittelalter zurückzuverlegen (vgl. etwa Wilhelm Molitor, Die Decretale per venerabilem von Innocenz dem Dritten und ihre Stellung im öffentlichen Rechte der Kirche, Münster 1876), doch kann diese Lehre erst im 16. Jahrhundert tatsächlich als voll ausformuliert angesehen werden.

5) Vgl. das in zahlreiche Sprachen übersetzte Handbuch von Isnard Wilhelm Frank, Kirchengeschichte des Mittelalters, 2. Aufl. Düsseldorf 2005, S. 115-119. Die Forschungen Sticklers schlagen sich auch erkennbar nieder bei Werner Goez, Art. „Zwei-Schwerter-Lehre“, in: Lexikon des Mittelalters 9, Sp. 725f. sowie Paul Mikat, Art. „Zweischwerterlehre“, in: LThK 10, Sp.1519f.

${ }^{6}$ ) Vgl. Percy Ernst Schramm, Sacerdotium und Regnum im Austausch ihrer Vorrechte, Eine Skizze der Entwicklung zur Beleuchtung des „Dictatus papae“ Gregors VII., in: Studi Gregoriani 2 (1947) 403-457. 
walt besitze ${ }^{\left({ }^{7}\right.}$ ).Während nach Ansicht Sticklers die Kirche schon seit der Konstantinischen Wende eine niedere materielle Zwangsgewalt theoretisch beansprucht und praktisch wahrgenommen habe, trat im 11. und 12. Jahrhundert auch der Anspruch auf die Blut- und Waffengewalt hinzu, was insbesondere in der Entstehung des Kreuzzugsgedankens sinnfällig geworden sei ${ }^{8}$ ). Neben der höchsten geistlichen Zwangsgewalt, der Exkommunikation, sollten damit der Kirche auch die höchsten Formen der materiellen Zwangsgewalt zur Verwirklichung und Durchsetzung ihrer geistlich-religiösen Ziele zustehen. Dieses kirchlich-materielle ius gladii müsse von der daneben existierenden rein weltlichen Gewalt des Kaisers und anderer Könige unterschieden werden, was jedoch seit dem 13. Jahrhundert nicht immer geschehen sei. Der Grund dafür liege in der Schwertmetapher, die seit dem ausgehenden 11. Jahrhundert sowohl für die höchste materielle Zwangsgewalt der Kirche als auch für die rein weltliche Gewalt des Kaisers und anderer Könige verwendet wurde. In der Ausübung des gladius materialis ecclesiae konnte der Kaiser ohne Zweifel als vicarius papae, minister ecclesiae und advocatus ecclesiae Romanorum ${ }^{9}$ ) bezeichnet werden, nicht aber in der Führung des eigenen, rein weltlichen Schwertes, das ihm von Gott (unmittelbar oder durch die Wahl der Fürsten/des Volks) anvertraut worden war. Stickler mahnte daher stets zu prüfen, ob in den Quellen unter dem gladius materialis die höchste materielle Zwangsgewalt der Kirche oder die rein weltliche Gewalt des Kaisers (und anderer Könige) gemeint war. Nicht immer, wenn es hieß, der Kaiser habe sein Schwert vom Papst erhalten, müssten damit hierokratische Ansichten einhergehen.

In einer Reihe von Einzeluntersuchungen versuchte Stickler den Gebrauch des gladius materialis ecclesiae u. a. bei Papst Gregor VII., Gratian, Huguccio

$\left.{ }^{7}\right)$ Alfons M. Stickler, Der Schwerterbegriff bei Huguccio, in: Ephemerides iuris canonici 3 (1947) 201-242, S. 218.

$\left.{ }^{8}\right)$ Vgl. auch Sascha Ragg, Ketzer und Recht, Die weltliche Ketzergesetzgebung des Hochmittelalters unter dem Einfluß des römischen und kanonischen Rechts, Hannover 2006, über die im 12. Jahrhundert zunehmend materiell-repressiven Maßnahmen der Kirche im Zuge der Ketzerbekämpfung.

${ }^{9}$ ) Eine Bezeichnung für den Kaiser, die eben erst Mitte des 12. Jahrhunderts Verbreitung fand. Vgl. dazu Werner Goez, Imperator advocatus Romanae ecclesiae, in: Hubert Mordek (Hg.), Aus Kirche und Reich, Studien zu Theologie, Politik und Recht im Mittelalter, Festschrift für Friedrich Kempf zu seinem fünfundsiebzigsten Geburtstag und fünfzigjährigen Doktorjubiläum, Sigmaringen 1983, S. 315-328 sowie Ulrich Schludi, Advocatus sanctae Romanae ecclesiae und specialis filius beati Petri, Der römische Kaiser aus päpstlicher Sicht, in: Stefan Burkhardt (Hg.), Staufisches Kaisertum im 12. Jahrhundert, Konzepte, Netzwerke, politische Praxis, Regensburg 2010, S. 41-73. 
und Bernhard von Clairvaux nachzuweisen, und seine Thesen wurden von der Forschung überwiegend positiv aufgenommen. Helmut Plechl schloss sich im DA der Einschätzung Sticklers an, dass nun ,alles bisher zum Thema Imperium und Sacerdotium Gesagte einer Revision unterzogen werden“ müss $\mathrm{e}^{10}$ ), und tatsächlich bemühten sich in der Folgezeit zahlreiche Untersuchungen unter Berufung auf die Forschungen Sticklers um eine Korrektur des vorherrschenden Geschichtsbildes, welches das Papsttum stets in einer ungebrochenen Linie von Gregor VII. zu Bonifaz VIII. als Verfechter der Hierokratie gesehen hatte. Stanley Chodorow argumentierte mit Stickler für ein dualistisches Gewaltenverständnis bei Gratian, der in seinem Decretum neben der weltlichen Gewalt der Fürsten auch eine materielle Zwangsgewalt der Kirche gekannt habe $\left.{ }^{11}\right)$. Elizabeth Kennan wies mit Stickler die vor allem von Augustin Fliche und Joseph Lecler ${ }^{12}$ ) vertretene Ansicht zurück, Bernhard von Clairvaux habe als Vertreter des Gregorianismus mit seiner Interpretation des Schwertergleichnisses nach Luk 22,38 dem Papsttum den Weg der Hierokratie gewiesen. Eine Interpretation der Zwei-Schwerter Allegorie in De consideratione im Sinne des gladius materialis ecclesiae füge sich letztlich wesentlich harmonischer in das Gesamtwerk Bernhards ein, als eine hierokratische Auslegung ${ }^{13}$ ). James Muldoon machte unter ausdrückli-

$\left.{ }^{10}\right)$ Rezension von Sticklers Aufsatz „Imperator Vicarius Papae“ in: Deutsches Archiv für Erforschung des Mittelalters [DA] 11 (1954/55) 605f.

${ }^{11}$ ) Vgl. Stanley Chodorow, Christian political theory and church politics in the mid-twelfth century, The ecclesiology of Gratian's decretum, Berkeley 1972, bes. S. 223-246. Als Nachweis für die Pflicht der weltlichen Gewalt, der Kirche als brachium saeculare zu Hilfe zu kommen dient C. 23, q. 5, dist. post c. 25: Preterea, sicut principibus et potestatibus fidem et reverentiam exhibere cogimur, ita secularium dignitatum amministrationibus defendarum ecclesiarum necessitas incumbit. Quod si facere contempserint, a communione sunt repellendi. Der gladius materialis ecclesiae im Sinne Sticklers könne bei Gratian gefunden werden in C.23, q.8, dist. post c.18: In registro enim legitur, quod B. Gregorius civibus Tusciae, ut contra Longobardos arma pararent, mandavit, et militantibus stipendia decrevit. Hoc igitur exemplo et premissis auctoritatibus claret, quod sacerdotes, etsi propria manu arma arripere non debeant, tamen vel his, quibus huiusmodi offitia conmissa sunt, persuadere, vel quibuslibet, ut ea arripiant, sua auctoritate valeant inperare.

${ }^{12}$ ) Augustin Fliche, L’influence de Grégoire VII et des idées Grégoriennes sur la pensée de Saint Bernard, in: Association Bourguignonne des Sociétés Savantes (Hg.), Saint Bernard et son temps, Bd. 1 Dijon 1928, S. 137-150; J oseph Lecler, L'argument des deux glaives dans les controverses politiques du Moyen Age, in: Recherches de science religieuse 21 (1931) 299-339, S. 312ff.

13) Elizabeth Kennan, The „De consideratione“ of St. Bernard of Clairvaux and the papacy in the mid-twelfth century, A review of scholarship, in: Traditio 23 (1967) 73-115. 
cher Berufung auf Sticklers Analyse der Schwertsymbolik auf den ebenfalls mehrdeutigen Begriff des imperium aufmerksam ${ }^{14}$ ). So habe die bei Gratian ursprünglich auf rein innerkirchliche Angelegenheiten bezogene Aussage nullum imperium extra ecclesiam erst in der zweiten Hälfte des 12. Jahrhunderts eine hierokratische Bedeutung erhalten, wonach ohne kirchliche Vermittlung überhaupt keine legitime weltliche Gewalt (imperium) existiere. In der äußerst kontrovers geführten Auseinandersetzung um das Gewaltenverständnis Papst Innozenz' III. griff vor allem Friedrich Kempf in seiner Argumentation für eine prinzipiell dualistische Grundhaltung des Papstes ebenfalls nachdrücklich auf die Thesen Sticklers zurück ${ }^{15}$ ). Arturo Rivera Damas machte den gladius materialis ecclesiae zur Grundlage seiner Untersuchung über das politische Denken des Hostiensis ${ }^{16}$ ), ebenso wie Rosalio Castilio Lara, der die Lehre des kirchlichen ius gladii von Alexander III. bis Bonifaz VIII. vor diesem Hintergrund nachzeichnete ${ }^{17}$ ). Für den französischen Theologen Yves Congar schließlich erfasste Sticklers Lesart des gladius materialis ecclesiae gar den „Sinn der Texte des heiligen Bernhard und der Mehrzahl der kirchlichen Texte bis einschließlich Bonifatius VIII.“" ${ }^{\text {18) }}$. Hatte am Ende also sogar Papst Bonifaz VIII. in seiner berühmten Bulle Unam Sanctam unter den beiden dem Papst zustehenden Schwertern nur die beiden höchsten Formen der geistlichen und materiellen Zwangsgewalt der Kirche verstanden und wollte dem Kaiser und den anderen weltlichen Königen gar nicht ihre rein weltliche Herrschaft streitig machen? Zweifellos konnten Sticklers Thesen dazu benutzt werden, das hoch- und spätmittelalterliche Papsttum vom Makel der Hierokratie reinzuwaschen ${ }^{19}$ ), wenn sie derart großzügig gehandhabt wurden. Tat-

${ }^{14}$ ) James M. Muldoon, Extra ecclesiam non est imperium, in: Studia Gratiana 9 (1966) 543-580.

15) Friedrich Kempf, Papsttum und Kaisertum bei Innocenz III., Die geistigen und rechtlichen Grundlagen seiner Thronstreitpolitik, Rom 1954.

${ }^{16}$ ) Arturo Rivera Damas, Pensamiento politico de hostiensis, Estudio jurídico, histórico sobre las relaciones entre el Sacerdocio y el Imperio en los escritos de Enrique de Susa, Zürich 1964.

${ }^{17}$ ) Rosalio J. Castillo Lara, Coaccion eclesiastica y sacro romano imperio, Estudio jurídico-histórico sobre la potestad coactiva material suprema de la iglesia en los documentos conciliares y pontificios del período de formación del derecho canónico clásico como un presupuesto de las relaciones entre sacerdotium e imperium, Augustae Taurinorum 1956.

${ }^{18}$ ) Yves Congar, Heilige Kirche, Ekklesiologische Studien und Annäherungen, Stuttgart 1966, S. 430.

$\left.{ }^{19}\right)$ Vgl. Hartmut Hoffmann, Die beiden Schwerter im hohen Mittelalter, in: DA 20 (1964) 78-114, S. 82. 
sächlich hatte bereits der Jesuitengelehrte Hermann Joseph Graf Fugger-Glött in einer kurzen und wenig beachteten Abhandlung über die „Staatsgefährlichkeit der katholischen Kirche“ aus dem Jahre 1875 eine Interpretation der mittelalterlichen Schwerterlehre vorgelegt, die das Ergebnis der Forschungen Sticklers im Kern vorwegnahm, und damit versucht, die Aussagen der Bulle Unam Sanctam als unhierokratisch zu erweisen.

„Wie eben bemerkt, geht aus diesem Zusammenhang der ganzen Bulle [Unam Sanctam] klar hervor, daß der Papst [Bonifaz VIII.] in derselben von der rein zeitlichen Gewalt nicht redet. Er spricht nur von der Kirche, und behauptet, daß die Kirche eine zeitliche, materielle Gewalt habe, etwas, was keinem Zweifel unterliegt, wenn die Kirche einen materiellen Organismus mit materiellen Rechten hat. (...) Dieses Recht des Schutzes ihres leiblichen Lebens nennt die Kirche von Alters her ihr zeitliches Schwert, und sieht es vorgebildet in jenem Schwerte, das Petrus im Garten zog, als der Verräther kam. Aber auch die Worte Christi zu Petrus bei dieser Gelegenheit hat die Kirche von jeher auf sich bezogen, indem sie darin den Willen des Herrn sah, daß die Kirche dieses Schwert nicht selbst handhabe. Sie legt es daher in die Hände der ,Könige und Krieger` und vor allem in die Hand des römischen Kaisers, den sie eben zum Kaiser salbte, daß er Schutzherr der Kirche sei ${ }^{{ }^{(20}}$ ).

Stickler selbst war in seinen Schlussfolgerungen zurückhaltender, aber auch er fragte vielsagend, ob denn Papst Bonifaz VIII. in seiner berühmten Bulle Unam Sanctam überhaupt die hierokratische Position zur Last zu legen sei, denn schließlich habe der Papst im Konsistorium (Juni 1302) die gegen ihn aus Frankreich erhobenen Vorwürfe energisch zurückgewiesen, wonach er sich auch die weltliche Gewalt des Königs anmaßen würde ${ }^{21}$ ). Wenn Bonifaz VIII. daher in Unam Sanctam und anderen päpstlichen Schreiben behauptet, dass Könige und Kaiser die Schwertgewalt vom Papst erhalten ${ }^{22}$ ), dann muss man entweder einen eklatanten Widerspruch in den päpstlichen Aussagen an-

${ }^{20}$ ) Herman Josef Fugger-Glött, Die Staatsgefährlichkeit der römisch-katholischen Kirche, Regensburg 1874, S. 39f.

${ }^{21)}$ Vgl. Karl Ubl, Die Genese der Bulle Unam Sanctam: Anlass, Vorlagen, Intention, in: Martin Kaufhold (Hg.), Politische Reflexion in der Welt des späten Mittelalters, Leiden 2004, S. 129-149, S. 133f. u. 141.

${ }^{22}$ ) Bulla „Unam Sanctam“, ed. Giovanni B. Lo Grasso, Ecclesia et status, Rom 1952, S. 212 : Uterque ergo in potestate ecclesiae, spiritualis scilicet gladius et materialis. Sed is quidem pro ecclesia, ille verbo ab ecclesia exercendus. Ille sacerdotis, is manu regum et militum, sed ad nutum et patientiam sacerdotis. Oportet autem gladium esse sub gladio, et temporalem auctoritatem spirituali subiici potestati. Vgl. auch Scriptum pontificis principibus electoribus directum (MGH Const. IV, 1, Nr. 105), S. 80: ... a qua [sc. Apostolica sedes] romanorum imperatores et reges (...) receperunt gladii potestatem; Forma donationis provinciae tusciae regi missa (MGH Const. IV, 1, Nr. 107), S. 82: ... a qua [sc. Apostolica sedes] reges et imperatores (...) recipiunt temporalis gladii potestatem. 
nehmen, oder aber, so Stickler, die übliche Gleichsetzung von potestas gladii und weltlicher Gewalt neu überdenken ${ }^{23}$ ).

Hans Barion, der die Arbeiten Sticklers zum gladius materialis ecclesiae ebenso wie die sich daran anschließenden Untersuchungen in mehreren gleichermaßen kritisch wie anregenden Rezensionen begleitete, sah nunmehr die Vertreter des traditionellen Geschichtsbildes in der Pflicht, die Richtigkeit ihrer Ansichten neu zu beweisen ${ }^{24}$ ). Angesprochen fühlen musste sich vor allem Walter Ullmann, der in seinen Forschungen die These vertrat, dass das mittelalterliche Papsttum seit Gelasius' I. ein im Kern unverändert gebliebenes hierokratisches Gewaltenverständnis hatte. Dem Vorwurf seiner Kritiker, er ignoriere dabei jegliches dualistische Gewaltenverständnis, das sich doch ebenfalls während des gesamten Mittelalters nachweisen lasse, versuchte Ullmann auszuweichen, indem er erklärte, mit seinen Studien nicht eine Geschichte der politischen Ideen an sich schreiben zu wollen, sondern lediglich bestrebt war, die Entwicklung der Papstgrundsätze aufzuzeigen: „Und dort gab es keinen Dualismus“25). Freilich musste Ullmann auch eine dualistische Interpretation des Decretum Gratiani angesichts von dessen überragender Bedeutung für die mittelalterliche Kanonistik zurückweisen, obwohl die als Privatarbeit entstandene Kirchenrechtssammlung keineswegs ohne Weiteres als Ausdruck des päpstlichen Selbstverständnisses gewertet werden kann. Es ist bedauerlich, dass Ullmann, der zweifelsohne ein intimer Kenner Gratians $w^{26}{ }^{26}$ ), keine dezidierte quellengestützte Erwiderung auf Sticklers Interpretation des Decretum gab $^{27}$ ), sondern lediglich in einer längeren Fußnote in eher allgemeiner Form Stellung bezog und erklärte:

„The opinion of A. M. Stickler (...), that the Decretum presents a dualism, is wholly erroneous. The ,dualist' view is unhistoric and contradicts the ideological development from the times of Leo I. and Gelasius I. onwards; it is distorting since the anti-thesis of ,State and Church' was quite alien to the medieval mind (the term Status, it will be noted, had to be invented to express what Gratian - or anyother

23) Vgl. Stickler, Schwerterbegriff (oben Anm. 7) 240.

${ }^{24}$ ) Rezension von Coaccion Eclesiastica y Sacro Romano Imperio, in: ZRG 74 Kan. Abt. 43 (1957) 358.

${ }^{25)}$ Rezension von Saggi storici intorno al papato, in: Historische Zeitschrift 191 (1960) 621.

${ }^{26}$ ) Einer Anekdote zufolge soll er das Decretum Gratiani als Bettlektüre bevorzugt haben, vgl. Horst Fuhrmann, Menschen und Meriten, Eine persönliche Portraitgalerie, München 2001, S. 236.

${ }^{27}$ ) Zum Vorwurf Sticklers, Ullmann habe bei seiner Untersuchung das Decretum nicht berücksichtigt, vgl. Alfons M. Stickler, Concerning the political theories of the medieval canonists, in: Traditio 7 (1949/51) 450-463. 
contemporary - could not express, because it was not there); it soley operates with the twentieth-century concept of ecclesia and entirely neglects the central (Augustinian) idea of ecclesia which was the fons et origio of all medieval ecclesiasticopolitical thinking. (...) it does violence to the tenet of the primatial position of the Roman Church and implicitly restricts the pope's function as vicarius Christi. (...) Indeed, such dualistic ,interpretations ' breath the spirit of the papally condemned anti-papalist literature and arguments of the $13^{\text {th }}$ and $14^{\text {th }}$ centuries. The failure of the modern interpreters is on a par with the eventual failure of the medieval antipapalists“28).

Eine ausführlichere und quellennahe Replik auf die Forschungen Sticklers ist Hartmut Hoffmann zu verdanken ${ }^{29}$ ). In seiner Studie über die beiden Schwerter im hohen Mittelalter liefert er eine Reihe von Belegen für eine monistische (hierokratische) Auslegung von Luk 22,38, doch Sticklers Interpretationen zum gladius materialis ecclesiae insbesondere bei Gratian, Bernhard von Clairvaux und Huguccio können von Hoffmann nicht in jeder Hinsicht zwingend widerlegt werden ${ }^{30}$ ). Schlagkräftig sind jedoch seine allgemein formulierten Kritikpunkte, die wie bei Ullmann auf den Vorwurf des Anachronismus hinauslaufen. Sticklers These stehe

„im Widerspruch zur geistigen Situation des Hochmittelalters. Sie setzt im Grunde eine Welt voraus, in der neben der Kirche ein Bereich vorhanden ist, der ohne religiöse Wertungen auskommt; wo der Herrscher (oder gar der Staat) mit Gewalt einschreitet, ohne daß der Seelsorger sich irgendwie darum kümmert; und wo eine Gerechtigkeit zu verwirklichen ist, die mit der himmlischen Gerechtigkeit unmittelbar nichts zu tun hat. Wir wissen aber, daß das hohe Mittelalter nicht in diesen

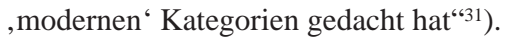

Nach Ansicht von Hoffmann waren die Gelehrten des 12. Jahrhunderts also gar nicht in der Lage, so etwas wie eine rein weltliche (Staats-)Gewalt zu denken. Die augustinische Idee der ecclesia universalis sei auch im 12. Jahrhundert der einzige Rahmen für politisch-herrschaftstheoretische Überlegungen gewesen, so dass die von Stickler in die Quellen hineingelesene Unter-

${ }^{28}$ ) Walter Ullmann, The Medieval Interpretation of Frederick I's Authentic „Habita“, L’ Europa e il diritto romano, Studi in memoria di Paolo Koschaker, Bd. 1 Milano 1954, S. 101-136, S. 106.

${ }^{29}$ ) Hoffmann (oben Anm. 19).

${ }^{30}$ ) Vgl. Elizabeth Kennan (oben Anm. 13) 103f., die auch nach Berücksichtigung von Hoffmanns Ausführungen die Interpretation Sticklers für überzeugender hält. Auch Wilhelm Kölmel, „A Deo sed per homines“. Zur Begründung der Staatsgewalt im Ordnungsverständnis des Mittelalters, in: Franziskanische Studien 48 (1966) 308-335, S. 312 Anm. 14 hält Hoffmanns Kritik an Stickler für nicht ausreichend begründet.

31) Hoffmann (oben Anm. 19) 80. 
scheidung in eine rein weltliche Gewalt und eine materielle Zwangsgewalt für kirchlich-religiöse Zwecke von vorneherein unmöglich sei. Demgegenüber sahen Stickler und Kempf im Investiturstreit eine entscheidende Zäsur im Verhältnis zwischen regnum/imperium und sacerdotium, die die Einheit der frühmittelalterlichen ecclesia universalis beendet habe. Die (Amts-)Kirche habe sich unter dem Schlachtruf der libertas ecclesiae als eigene Korporation von der weltlich-laikalen Sphäre des regnum/imperium abgegrenz $\mathrm{t}^{32}$ ), das seinerseits nun vor allem unter Rückgriff auf das wiederentdeckte römische Recht „seinen früheren, auf der Weihe und auf dem Dienst an der ecclesia universalis beruhenden Herrschaftsanspruch um[wandelte] zu einem Königtum durch göttliches Recht, zur Herrschaft über einen eigenständigen, kraft der direkt von Gott verliehenen potestas zu verwaltenden Rechts- und Aktionsbereich, den es während der zwei Jahrhunderte [nach dem Investiturstreit] immer zielbewußter ausbaute und langsam der Souveränität entgegenführte“333). Die Bedeutung des Investiturstreits als grundlegende (ideen) geschichtliche und staatstheoretische Zäsur wird zwar seit vielen Jahren kontrovers diskutiert ${ }^{34}$ ), neuere Forschungen zeigen jedoch, dass es gute Gründe

${ }^{32}$ ) Friedrich Kempf, Die Katholische Lehre von der Gewalt der Kirche über das Zeitliche in ihrer geschichtlichen Entwicklung seit dem Investiturstreit, in: Catholica 12 (1958) 50-66, S. 52f. Vgl. auch J. Miethke, Kirchenstruktur und Staatstheorien im Zeitalter der Scholastik, in: Bernd Schneidmüller u.a. (Hgg.), Ordnungskonfigurationen im hohen Mittelalter, Ostfildern 2006, S. 127-151, S. 130; Ernst-Wolfgang Böckenförde, Die Entstehung des Staates als Vorgang der Säkularisation, Säkularisation und Utopie, Ebracher Studien, Ernst Forsthoff zum 65. Geburtstag, Stuttgart 1967, S. 75-94; Heike Johanna Mierau, Kaiser und Papst im Mittelalter, Köln 2010, S. 169.

33) Friedrich Kempf, Zur politischen Lehre der früh- und hochmittelalterlichen Kirche, in: ZRG 78 Kan. Abt. 47 (1961) 305-319, S. 307. In einem Aufsatz von 1973 vertrat auch Ullmann die Ansicht, dass der Angriff des Reformpapsttums auf die sakrale Herrschaftslegitimation von König- und Kaisertum dazu geführt habe, dass sich regnum und imperium mit Hilfe des römischen Rechts eine neue, säkulare Legitimationsgrundlage geschaffen haben. Walter Ullmann, Von Canossa nach Pavia, Zum Strukturwandel der Herrschaftsgrundlagen im salischen und staufischen Zeitalter, in: Historisches Jahrbuch 93 (1973) 265-300, S. 297. Mit „all medieval ecclesiasticopolitical thinking“ (vgl. Anm. 28) scheint Ullmann also letztlich nur die päpstlich gesinnten Theologen und Kanonisten gemeint zu haben, während offenbar auch nach Ansicht Ullmanns die Legisten und vom römischen Recht beeinflusste Kanonisten bereits im 12. Jahrhundert durchaus eine andere politische Ordnungskonfiguration als die augustinische ecclesia universalis im Sinn haben konnten.

${ }^{34}$ ) Vgl. den Überblick bei Wilfried Hartmann, Der Investiturstreit, 3. Aufl. München 2007, S. 101ff. sowie zuletzt ablehnend Hartmut Hoffmann, Canossa eine Wende?, in: DA 66 (2010) 535-568. 
gibt, die vor allem in der deutschen Mediävistik lange Zeit vorherrschende grundsätzliche Ablehnung gegen früh- und hochmittelalterliche Konzepte von Staatlichkeit neu zu hinterfragen ${ }^{35}$ ). Auch wenn der entscheidende Durchbruch in der herrschaftstheoretischen Fundierung staatlicher Eigenständigkeit erst mit der großen Aristotelesrezeption in der zweiten Hälfte des 13. Jahrhunderts erfolgte, so war doch schon im 12. Jahrhundert ein Prozess im Gange, der den weltlich-staatlichen Bereich als politische Ordnungskonfiguration erkennbar werden lie $\left.\aleph^{36}\right)$. Allerdings, das gaben auch Stickler und Kempf zu, war die rechtliche, theoretische und begriffliche Fixierung der weltlich-staatlichen Sphäre noch nicht in dem Maße entwickelt, wie das bei der (Amts-)Kirche der Fall war ${ }^{37}$ ); und schon gar nicht kann für das 12. Jahrhundert von einem rein säkularen Staatsbegriff gesprochen werden, schon allein deshalb, weil die Folgen des Investiturstreits, wie bereits Ernst-Wolfgang Böckenförde bemerkte, noch „nicht die Entlassung [der weltlich-staatlichen Sphäre] aus der religiösen Fundierung schlechthin “ bewirkten ${ }^{38}$ ). Nur: Reicht ein derartiger „Staatsbegriff“ aus als Grundlage für eine Theorie, wie sie Stickler vorlegte? Hier sind Zweifel, wie sie von Hoffmann geäußert wurden, durchaus berechtigt. Und auch Stickler und Kempf sahen in dem nicht voll

35) Vgl. E.-D. Hehl, Krieg, Individualisierung und Staatlichkeit im ausgehenden 11. und im 12. Jahrundert, in: Klaus Herbers (Hg.), Europa an der Wende vom 11. zum 12. Jahrhundert, Beiträge zu Ehren von Werner Goez, Stuttgart 2001, S. 117-133, Stuart Airlie u.a. (Hgg.), Staat im frühen Mittelalter, Wien 2006 sowie Walter Pohl u.a. (Hgg.), Der frühmittelalterliche Staat - europäische Perspektiven, Wien 2009.

${ }^{36}$ ) Vgl. Hans Hubert Anton, Anfänge säkularer Begründung von Herrschaft und Staat im Mittelalter, Historiographie, Herkunftssagen, politische Metaphorik (Institutio Traiani), in: Archiv für Kulturgeschichte 86 (2004) 75-122; Böckenförde, Entstehung (oben Anm. 32) 78ff.; Hans Maier, „Canossa“ heute-Mythos und Symbol, in: Christoph Stiegemann u.a. (Hgg.), Canossa 1077 - Erschütterung der Welt, Geschichte, Kunst und Kultur am Aufgang der Romanik, Bd. 1 München 2006, S. 625-630, sieht sogar „im Zeitalter des Investiturstreits wichtige, bis heute gültige Züge moderner Staatlichkeit“ (S. 625) auf den Weg gebracht.

${ }^{37}$ ) Friedrich Kempf, Caput Christianitatis, Ein Beitrag zum Verständnis des mittelalterlichen Papsttums, in: Stimmen der Zeit 158 (1955/56) 91-100, S. 93; Alfons M. Stickler, Imperator vicarius Papae, Die Lehren der französisch-deutschen Dekretistenschule des 12. und beginnenden 13. Jahrhunderts über die Beziehungen zwischen Papst und Kaiser, in: Mitteilungen des Instituts für Österreichische Geschichtsforschung 62 (1954) 165-212, S. 210f. Vgl. auch Maier (oben Anm. 36) S. 626.

$\left.{ }^{38}\right)$ Böckenförde, Entstehung (oben Anm. 32) 81; vgl. auch Martin Rhonheimer, Christentum und säkularer Staat, Geschichte - Gegenwart - Zukunft, Freiburg im Breisgau 2012, S. 78. 
entwickelten säkularen Staatsbegriff einen entscheidenden Fallstrick für die Lehre vom gladius materialis ecclesiae. Denn dieser sich seiner selbst im 12. Jahrhundert zunehmend bewusst werdende weltlich-staatliche Bereich beanspruchte nach wie vor, seine Gewalt unmittelbar von Gott zu erhalten und eine genuine, von Gott unmittelbar übertragene Verantwortung zum Schutz der Kirche und des katholischen Glaubens zu besitzen. Mit anderen Worten, die „rein weltliche“ Gewalt beschränkte sich nicht auf „rein weltliche“ Aufgaben, sondern wurde auch bei der Verteidigung der christlichen Religion mit ihrem eigenen Schwert aktiv, so dass - folgt man Stickler - in diesem Bereich gewissermaßen zwei materielle Schwerter (das rein weltliche und der gladius materialis ecclesiae) aktiv waren oder, wie Hans Barion meinte, ein doppeltes brachium saeculare angenommen werden muss ${ }^{39}$ ). Die Frage, auf welcher Rechtsgrundlage das brachium saeculare eigentlich beruhte, ist in der modernen kanonistischen Forschung als problème délicat erkannt worden, das in der Regel mit einem entweder (aufgrund staatlicher Jurisdiktion) - oder (aufgrund delegierter kirchlicher Jurisdiktion) beantwortet wird ${ }^{40}$ ). Sticklers Interpretation hingegen lief auf ein Sowohl-als-auch hinaus, indem er versuchte, zwei unterschiedliche Rechtsgrundlagen für die Verteidigung der Kirche mit Waffengewalt nachzuweisen ${ }^{41}$ ). Zum einen die Verpflichtung „der weltlichen Autorität, mit ihrem materiell-zeitlichen Zwang kirchliche Interessen wahrzunehmen; (...) der Kirche unter die Arme zu greifen u. zw. in jenen kirchlichen Angelegenheiten, die nicht anders als durch materiell-zeitliche Zwangsanwendung gelöst werden können“42). Diese Verpflichtung habe „der Staat (...) kraft eigener staatlicher Jurisdiktion“ “43), d.h. mit seinem eigenen

$\left.{ }^{39}\right)$ Rezension zu Coaccion Eclesiastica (oben Anm. 24) 356.

${ }^{40}$ ) Vgl. Laprat (oben Anm. 2) Sp. 981: „... la doctrine de l'aide séculière à l'Église: c'est une partie, et non la moindre, de la théorie des rapports entre l’Église et l’Ètat. (...) Le problème est particulièrement délicat. La justice temporelle pourra-t-elle discuter les conditions de son concours ou sera-t-elle obligée d'apporter son aide au tribunal ecclésiastique? Question de supériorité d’une justice sur l'autre qui va devenir singulièrement ardue à mesure par le Moyen Age chrétien.“

$\left.{ }^{41}\right)$ Eine Unterscheidung, die im Wesentlichen der von Reinhold Sebott geforderten Differenzierung von brachium saeculare und cura religionis entspricht. Vgl. Reinhold Sebott, Religionsfreiheit und Verhältnis von Kirche und Staat, Der Beitrag John Courtney Murrays zu einer modernen Frage, Rom 1977, S. 86 Anm. 85: „Zumindest theoretisch müssen die beiden Probleme der cura religionis und des brachium saeculare auseinandergehalten werden. Im ersteren Falle fragt man, ob der Staat von sich aus in Sachen der Religion eingreifen kann, im zweiten Fall, ob er von der Kirche gezwungen werden kann, einzugreifen.“

$\left.{ }^{42}\right)$ Stickler, Schwerterbegriff (oben Anm. 7) $217 f$.

43) Stickler, Imperator (oben Anm. 37) 182. 
gladius materialis, zu erfüllen, wozu er aber notfalls auch „durch kirchlichgeistige Zwangsmittel [ge]zwungen werden kann“44). In den Fällen aber, in denen die weltliche Gewalt dieser Verpflichtung nicht nachkomme, könne die Kirche zum anderen auf ihren eigenen gladius materialis ecclesiae zurückgreifen. Ausgeübt werde dieses Waffenrecht der Kirche freilich wiederum durch „die Laien, sowohl die Fürsten als auch alle anderen, und zwar auf die Autorität der Kirche hin, die dies allen Laien ohne Unterschied befehlen kann. Sie kann alle auffordern, für die Interessen der Kirche auch mit Waffengewalt einzutreten, wenn es nötig ist; ja sie kann über ihre geistigen Zwangsmittel dazu zwingen“45). Abgesehen von der theoretischen Rechtsgrundlage fällt es schwer, hier einen praktischen Unterschied zwischen der rein weltlichen Gewalt und der materiellen Zwangsgewalt der Kirche auszumachen. Die Dopplung des brachium saeculare erfolgt letztlich durch die Unterscheidung in Idealfall und Notfall. Im Idealfall eines einträchtigen Zusammenwirkens stellt der Fürst sein weltliches Schwert bereitwillig (gegebenenfalls auch erst nach kirchlicher Ermahnung) in den Dienst der Kirche. Sollte der Fürst sich aber auch unter Androhung der Exkommunikation nicht dazu bereit erklären, kann der Papst kraft eigener Autorität auf einen kircheneigenen gladius materialis zurückgreifen, welchen er jedoch nicht selber führen darf, sondern an andere Laien(-fürsten) zu delegieren hat.

Stickler sieht in der Ähnlichkeit der beiden materiellen Schwerterbegriffe den Grund für jene Begriffsverwirrung, die seiner Ansicht nach unter den Kanonisten im 13. Jahrhundert um sich gegriffen und zum Siegeszug der hierokratischen Lehre geführt habe.

„Der eigentliche und tiefste Grund dürfte wohl darin liegen, dass praktisch die Anwendung der kirchlichen Zwangsgewalt immer auf die Laien zurückfiel und dazu, aus naheliegenden Gründen der Durchführungsmöglichkeit, auf die Fürsten, die schon über eine eigene, weltliche Zwangsgewalt verfügten. So erscheint als Träger dieser Gewalt die staatliche Obrigkeit und in ihrem Verhältnis zur Kirche wird eben vor allem diese Funktion gesehen und damit unvermerkt (durch die Gedankengleichschaltung: materielle Schwertgewalt der Kirche ausschließlich durch die weltlichen Behörden ausgeübt) die Gleichung vollzogen: materielles Schwert - weltliche Gewalt. Man vergaß dann umso leichter, dass es sich um das materielle Schwert der Kirche gehandelt hat, als ja die weltliche Gewalt auch ihr eigenes Schwert, die ihr allein zur Verfügung stehende weltliche Zwangsgewalt, aus göttlicher Bestimmung schon immer in den Dienst der Kirche zu stellen verpflichtet war $\left.{ }^{\star 46}\right)$.

\footnotetext{
44) Stickler, Schwerterbegriff (oben Anm. 7) 217.

45) Stickler, Imperator (oben Anm. 37) 188.

${ }^{46}$ ) Stickler, Schwerterbegriff (oben Anm. 7) 230.
} 
Das doppelte brachium saeculare, oder besser: die doppelte Rechtsgrundlage des brachium saeculare, hat unlängst auch Sascha Ragg herausgearbeitet und gezeigt, wie die weltlichen Fürsten seit dem frühen 12. Jahrhundert von der Kirche im Zuge der Ketzerbekämpfung zunehmend in die Pflicht genommen wurden, wobei sich neben der kirchlichen auch eine auf dem spätantiken römischen Recht basierende eigene weltliche Ketzergesetzgebung entwickelte, so „dass die Grenzen zwischen kirchlicher und weltlicher Rechtssphäre im Falle des Häresiedelikts zu verschwimmen begannen““77). Das Wirken der weltlichen Fürsten als brachium saeculare konnte also auch auf einer kirchenunabhängigen Rechtsgrundlage erfolgen. In der Praxis spielte sich in einigen Regionen ein weitgehend einträchtiges Miteinander von geistlicher und weltlicher Gewalt ein: die Kirche überführte und verurteile die Ketzer und überstellte sie zur Vollstreckung der Strafe an die jeweiligen weltlichen Machthaber. Doch im Konfliktfall zwischen geistlicher und weltlicher Gewalt wurde alsbald die Frage aufgeworfen, inwieweit die Kirche die Unterstützung der weltlichen Fürsten überhaupt einfordern konnte ${ }^{48}$ ) - eine Frage, die nach Ansicht Sticklers durch die Unterscheidung in rein weltliche Gewalt und materielle Zwangsgewalt der Kirche (gladius materialis ecclesiae) hätte beantwortet werden können, ohne die Grundsatzproblematik des Gewaltenverhältnisses aufzuwerfen ${ }^{49}$ ), wie es infolge der Begriffsverwirrung seit dem frühen 13. Jahrhundert zumeist geschehen sei50).

$\left.{ }^{47}\right)$ Ragg (oben Anm. 8) 284.

${ }^{48}$ ) Zur Lösung der Untertanen vom Treueeid und der kirchlichen Fürstenabsetzung vgl. die Quellenverweise bei Ragg ebd. 93ff.

${ }^{49}$ ) Vgl. ebd. 100: „Die Frage, auf welche Art die Kurie nachlässige Fürsten zum Vorgehen gegen Ketzer zwingen konnte, verband sich schon unter Innozenz III. mit der Frage des Herrschaftsprimats des Papsttums gegenüber weltlichen Herrschern.“

${ }^{50}$ ) Auch die kaiserliche Seite ist nach Ansicht Sticklers dieser Begriffsverwirrung erlegen, habe sie doch im 13. Jahrhundert wiederholt versucht, ihr Recht auf materielle Zwangsgewalt in kirchlichen Angelegenheiten mit dem römischen Patriziat und der Rolle als advocatus ecclesiae Romanorum zu begründen, und „damit die Funktion, die sie zum Wohl der geistlichen Angelegenheiten und somit auch der Kirche als der einzig anerkannten mittelalterlichen religiösen Gemeinschaft als weltlicher Herrscher, d. h. schon auf Grund und kraft ihrer weltlichen Jurisdiktion haben, mit der kirchlichen, d.h. der kirchlichen Obrigkeit eigenen höchsten materiellen Zwangsprärogative, die alleine der Papst verleihen kann, verwechselt“, Stickler, Imperator (oben Anm. 37) S. 211 [Hervorhebung im Original gesperrt]. Dazu kritisch Wilhelm Kölmel, Regimen christianum, Weg und Ergebnisse des Gewaltenverhältnisses und des Gewaltenverständnisses (8. bis 14. Jahrhundert), Berlin 1970, S. 225; Hoffmann (oben Anm. 19) 82 und Ulrich Duchrow, Christenheit und Weltverantwortung, Traditionsgeschichte und systematische Struktur der Zweireichelehre, 2. 
Die Interpretationen der zahlreichen Glossen und Summenpassagen durch Stickler können hier nicht im Einzelnen nachvollzogen werden, doch auch wenn die Quellen längst nicht so eindeutig im Sinne des gladius materialis ecclesiae ausgelegt werden können, wie Stickler unermüdlich glaubt hervorheben zu müssen, so zeigen seine Untersuchungen doch, wie schwer die Rolle der weltlichen Gewalt als brachium saeculare rechtlich zu fassen war, und wie die Schwertmetapher von ein und demselben Kanonisten unterschiedlich gebraucht werden konnte ${ }^{51}$ ). Huggucio etwa sah in seinen Glossen zu D.63 c.22 den gladius materialis im Besitz des Papstes, der lediglich den actum executionis nicht selbst wahrnehmen dürfe und daher diesen an die Laienfürsten delegiere ${ }^{52}$ ). In einer Glosse zu D.96 c.6 hingegen erklärt Huguccio unter ausdrücklichem Verweis auf die Zwei-Schwerter-Lehre nach Luk 22,38, dass der Kaiser potestas gladii und executio gladii nicht vom Papst, sondern unmittelbar von Gott bzw. durch die Wahl von Volk und Fürsten verliehen bekomme $\left.{ }^{53}\right)$.

Aufl. Stuttgart 1983, S. 369. Zur unterschiedlichen Auslegung der Formel Imperator advocatus Romanae ecclesiae vgl. auch G oez, Imperator (oben Anm. 9), der gezeigt hat, wie sich neben der kirchlichen, die dienende Funktion des advocatus hervorhebenden Interpretation insbesondere unter Kaiser Friedrich II. eine Interpretation nach germanischem Rechtsverständnis finden lässt, wonach Schutz immer auch Herrschaft impliziere und sich somit „politisch-militärische Ansprüche (...) aus der kaiserlichen Vogtei über den Apostolischen Stuhl“ (S. 328) ableiten ließen. Dazu auch Schludi (oben Anm. 9) 45ff.

51) Vgl. dazu zuletzt kursorisch Mierau (oben Anm. 32) 170.

${ }^{52)}$ Huguccio zu D.63 c.22 ad v. „patriciatus dignitatem“, ed. Stickler, Schwerterbegriff (oben Anm. 7) 220 Anm. 2: hec dignitas erat quedam iurisdictio, quam papa alicui laic concedebat, scilicet ut seculares causas tractaret et crimina corporaliter puniret. Hanc iurisdictionem forte modo habet prefectus et secundum hoc potest intelligi illud cap.II, q.VI omnis oppressus. Et est ar. quod ecclesia potest concedere gladium sanguinis, licet per se illum agitare non debeat. Set sepe per alios possumus quod non per nos ut di. LXXXVIII episcopus gu.(bernationem c. 7). Habet ergo papa talem potestatem nudam et eius executionem et eam nudam concedit; set ex ea concessa alicui statim ei conceditur executio que ex ea pendet. Set credo quod papa et potestatem talem habeat et executionem, i. e. ius executionis, set non actum exequendi.; vgl. auch ad v. „non abet“, ebd. S. 222 Anm. 2.: non habet ecclesia gladium materialem in exercitio. Plures tamen ecclesiae habent gladium materialem quo ad potestatem et prestant auctoritatem exercendi eum in suo patrimonio et maxime ecclesia romana. Et potest delegare tamen gladium, licet diffiniere vel executionem demandare non possit. Die Delegierung des actum executionis des gladius materialis ecclesiae bezieht sich dabei keineswegs nur auf das Patrimonium, d. h. die unmittelbar weltlichen Besitztümer der römischen Kirche, sondern ausdrücklich auf die gesamte ecclesia Romana; vgl. auch Stickler, Schwerterbegriff (oben Anm. 7) $227 \mathrm{f}$.

53) Huguccio zu D.96 c.6, ed. Stickler, Schwerterbegriff (oben Anm. 7) S. 210f.: 
In derartigen Aussagen spiegeln sich die unterschiedlichen Traditionsströme wider, die in der mittelalterlichen Debatte um das Kaisertum wirksam werden konnten. Und diese verschiedenen „Konzepte des Kaisertums““54) mit ihren „heterogenen Grundelementen“55) waren letztlich nur schwer in Einklang zu bringen. Bereits im 12. Jahrhundert war mit der lex regia ein Grundsatz des im ausgehenden 11. Jahrhundert wiederentdeckten römischen Rechts auch in der Kanonistik nachweisbar und damit der Gedanke, dass der Kaiser seine Macht vom Volk habe $\left.{ }^{56}\right)$. Die in der mittelalterlichen Kanonistik viel diskutierte Frage, von wem der Kaiser sein Schwert empfing, kannte im späten 12. und 13. Jahrhundert zwar nur die Alternativen mediante papa oder immediate a Deo, wobei unter Letzterer aber bereits auch die Argumente fir-

... Hinc aperte colligitur quod utraque potestas, scil. apostolica et imperialis, sit a Deo et quod neutra pendeat ex altera et quod imperator gladium non habeat ab apostolico, ar. hic et infra eod. In scripturis, Duo, Si imperator (c.8, 10, 11) et Di.93 Legimus (c.24) et 24 q.4 Quaesitum (c.45). Ar. contra 22 Di. c.1 et Di.63. Tibi domino, In synodo (c. 33,23), et 15 q.6 Alius, Nos sanctorum, Iuratos (c.3, 4, 5) et 1 q.4. Quia praesulalus (c.5), et infra eod. Duo (c.10), et Di.21 Quamvis (c.3). Ex his omnibus contrariis introductis colligi videtur, quod imperator potestatem gladii et imperium habeat ab apostolico et quod eum faciet imperatorem papa et quod posset eum deponere. Ego autem credo, quod imperator potestatem gladii et dignitatem imperialem habet non ab apostolico, sed a principibus et populo per electionem, ut di.93 Legimus (c.24). Ante enim fuit imperator quam papa, ante imperium quam papatus. Item in figura hujus rei, quod discretae et diversae sint illae duae potestates, scil. imperialis et apostolica, dictum fuit: ecce duo gladii. Si ergo alicubi inveniatur et innuatur, quod imperator habet potestatem gladii a papa, sic intelligo, i. e. unctionem et confirmationem, quam a papa accipit et jurat ei fidelitatem. Ante quidem imperator est quoad dignitatem, sed non quoad unctionem, licet ante non dicatur imperator; et ante habet potestatem gladii et eam exercet. Vgl. Karl-Gottfried Hugelmann, Die Wirkungen der Kaiserweihe nach dem Sachsenspiegel, in: ZRG 40 Kan. Abt. 9 (1919) 1-62, S. 22f.

$\left.{ }^{54}\right)$ Rudolf Schieffer, Konzepte des Kaisertums, in: Bernd Schneidmüller u. a. (Hgg.), Heilig - Römisch - Deutsch, Das Reich im mittelalterlichen Europa, Dresden 2006, S. 44-56.

$\left.{ }^{55}\right)$ Friedrich Kempf, Das mittelalterliche Kaisertum, Ein Deutungsversuch, Das Königtum, Seine geistigen und rechtlichen Grundlagen, Lindau 1956, S. 225242, S. 235. Vgl. auch Anm. 47.

${ }^{56}$ ) Vgl. Dagmar Unverhau, Approbatio - Reprobatio, Studien zum päpstlichen Mitspracherecht bei Kaiserkrönung und Königswahl vom Investiturstreit bis zum ersten Prozeß Johanns XXII. gegen Ludwig IV., Lübeck 1973, S. 137ff. ; Andreas Kosuch, Abbild und Stellvertreter Gottes, Der König in herrschaftstheoretischen Schriften des späten Mittelalters, Köln 2011, S. 54-64. Die lex regia schlug sich bereits in kanonistischen Quellen Mitte des 12. Jahrhunderts nieder, vgl. Rufinus, Summa decretorum, ed. Heinrich Singer, Paderborn 1902, S. 13, D.4. 
mierten, die die päpstliche Vermittlung mit Hinweisen auf eine Wahl des Kaisers durch Fürsten, Volk und Heer ablehnten ${ }^{57}$ ). Erst im 14. Jahrhundert wurde dezidierter auch die Möglichkeit des imperium a populo diskutiert, wobei es mit Hilfe von zum Teil ausgefeilten Begriffsbestimmungen immer wieder gelang, gewisse Widersprüche aufzulösen ${ }^{58}$ ). Auch der Begriff der Schwertgewalt wurde von den mittelalterlichen Juristen schon im 12. Jahrhundert hinsichtlich zahlreicher Aspekte unterschieden. Die von Rufinus eingeführte Differenzierung der Gewalt in ius auctoritate und ius administrationis ${ }^{59}$ ) wur-

${ }^{57}$ ) Vgl. Kosuch (oben Anm. 56) 83, $293 f f$.

${ }^{58}$ ) Das berühmte imperium a deo, imperator a populo etwa konnte durch die Unterscheidung zwischen Amt und Person göttliches und menschliches Wirken bei der Konstituierung kaiserlicher Herrschaft plausibel in Einklang bringen. Cynus da Pistoia ad D. 1.1.14 §4 n.1 (Comm. in Cod. et aliquot titulos primi Pandectorum, fol. 8rb): Imperium est a Deo [...] et ab ipso Deo immediate processit, unde Imperatorem et Deum non est ponere medium. [...] Vel melius dico quod Imperator a populo est sed imperium, cuius presidatu Imperator dicitur divinus, a Deo. Vgl. Helmut G. Walther, Imperiales Königtum, Konziliarismus und Volkssouveränität, Studien zu den Grenzen des mittelalterlichen Souveränitätsgedankens, München 1976, S. 124, 175. Später distinguierte Wilhelm von Cremona den Begriff imperium noch weiter, vgl. Ko such (oben Anm. 56) 208 .Weitere Formeln wären etwa: Franciscus Accursius, Glossa in volumen, ed. Mario Viora, Augustae Taurinorum 1969, 244, Nov.73, Pr.1, ad. De coelo: Immo populus Romanus de terra: ut Inst. de iure na.§. sed et quod princ., que est contra. Sed deus constituit permittendo, et populus, Dei dispositione. Vel dic, Deus constituit auctoritate, populus ministerio; Ockham, III Dial. II, i, c. 26, ed. Jürgen Miethke, Texte zur politischen Theorie, Exzerpte aus dem Dialogus, Stuttgart 1995, S. 278: Quia cum dicitur, quod potestas imperialis et universaliter omnis potestas licita et legitima est a deo, non tamen a solo deo, sed quedam est a deo per homines. Et talis est potestas imperialis, que est a deo, sed per homines.

${ }^{59}$ ) Rufinus (oben Anm. 56) S. 47 zu D.22 c.1 ad v. terreni simul et celestis imperii iura commisit: Celeste imperium celestium militum, i. e. clericorum universitatem cum his que ad eos pertinent, dicit; terrenum vero regnum vel imperium seculares homines secularesque res appellat. Per hoc ergo videtur quod summus pontifex qui beati Petri est vicarius, habet iura terreni regni. Sed animadvertendum est quod ius aliud est auctoritatis, aliud amministrationis. Et quidem ius auctoritatis quemadmodum in episcopo, ad cuius ius omnes res ecclesiastice spectare videntur, quia eius auctoritate omnia disponuntur, ius autem amministrationis sicut in yconomo: iste habet ius amministrandi, sed auctoritate caret imperandi; quicquid allis precipit, non sua, sed episcopi auctoritate indicit. Summus itaque patriarcha quoad auctoritatem ius habet terreni imperii, eo scil. modo quia primum sua auctoritate imperatorem in terreno regno consecrando confirmat et post tam ipsum quam reliquos seculares, istis secularibus abutentes, sola sua auctoritate pene addicti et ipsos eosdem post penitentes absolvit. Ipse vero princeps post ipsum auctoritatem habet seculares regendi et preter ipsum officium amministrandi. 
de von der Quaestio Bambergensis noch erweitert, indem die Ausübung der Schwertgewalt (exercitium potestatis) noch einmal in ein exercitium quoad praeceptum und ein exercitium quoad usum unterteilt wurde ${ }^{60}$ ). Auch Huguccio unterschied in seiner Glosse zu D.63 c.22 die grundsätzlich dem Papst zustehende potestas gladii in ein beim Papst liegendes Ausübungsrecht (ius executionis) und einen an die Laienfürsten delegierten Ausübungsakt (actum executionis) ${ }^{61}$ ). Und nach Ansicht Sticklers hätte auch eine Distinktion in gladius materialis (im Sinne der rein weltlichen Gewalt) und gladius materialis ecclesiae (im Sinne der höchsten materiellen Zwangsgewalt der Kirche) ihre kirchenrechtliche Fundierung und Berechtigung gehabt - allein sie findet sich nirgends, wie Hartmut Hoffmann süffisant ${ }^{62}$ ), Stickler selbst hingegen mit großem Bedauern feststellt. Die Verwendung der Schwertmetapher durch Huguccio im jeweiligen Kontext der Glosse sowie die darin zitierten Parallelstellen zeigten nach Ansicht Sticklers zwar, dass der große Bologneser Kanonist

${ }^{60}$ ) Alfons M. Stickler, De potestate gladii materialis Ecclesiae secundum Quaestio Bambergensis ineditas, in: Salesianum 6 (1944) 113-140, S. 122: Attende, lector, quia non potestas secernitur, set officia separantur. Indecens enim apostolice celsitudini, ut que misericordie tota incumbit, nocentium cruore maculetur. Huiusmodi amministrationem a se prorsus reiecit quoad usum, set retinuit quoad preceptum. Quad tibi ex multis capitulis innotescat, si ultimam questionem XXIII cause fueris perscrutatus, ubi ab apostolico bellum indicitur et sanguis innoxius armorum violentia defensatur. [...] Ex eo autem quod spiritualis dumtaxat gladius apostolice sublimitati legitur attributus, callide posset presumi quod apostolicus dare non possit quod habere prohibetur, quia nemo non dat quod non habet. Hanc autem obiectionem facile elides, si ea que superius de auctoritate et amministratione iuris dicta sunt attendis.

61) Vgl. Anm. 52. Die Dekretsumme Reverentia sacrorum canonum stellte Ende des 12. Jahrhunderts angesichts solcher Distinktionen die Frage, ob der Papst, der zwar die potestas gladii besitze und auf den Kaiser übertrage, überhaupt als der Verleiher des usus gladii angesehen werden könne. Streng genommen verlieh er damit nämlich mehr, als er eigentlich besaß, und daher, so schließt der anonyme Glossator, habe der Kaiser zumindest den usus gladii direkt von Gott. Summa Reverentia sacrorum canonum zu D.10 c.8 ad. v. dignitatibus distinctis, ed. Stickler, Imperator (oben Anm. 37) 204 Anm. 69: Quibusdam tamen videtur quod [imperator] a summo ponifice eam [gladii potestatem] habeat, usum autem eius a Deo. Andere Kanonisten (Tancred, Alanus) wiederum vertraten die Ansicht, der Kaiser habe zwar das imperium von Gott, das Recht, seine Gewalt auch auszuüben aber von der Kirche. Vgl. die Glossa ordinaria (Bernardus Parmensis) zu X. IV, 17, 7 ad. v. ad regem: ... Sed Alan(us) et Tan(credus) dixerunt, quod imperator, licet imperium a solo Deo dicatur processisse, exsecutionem gladii temporalis recepit ab ecclesia. Vgl. Othmar Hageneder, Das päpstliche Recht der Fürstenabsetzung: Seine Kanonistische Grundlegung (1150-1250), in: Archivum Historiae Pontificiae Bd. 1 (1963) 53-95, S. 82f.

${ }^{62}$ ) Vgl. Hoffmann (oben Anm. 19) 80. 
zwei unterschiedliche Bedeutungsinhalte unter dem Begriff des materiellen Schwertes subsumierte ${ }^{63}$ ), eine ausdrückliche Distinktion treffe er in diesem Punkt jedoch nicht. Offenbar, so mutmaßt Stickler, war sich Huguccio des doppelsinnigen Schwerterbegriffs selbst nicht voll bewusst ${ }^{64}$ ).

„Es wäre vielleicht eines der grössten Verdienste Huguccios gewesen, hätte er diese Probleme gesehen und mit seiner gewohnten Schärfe aufgezeigt und gelöst, wenn man damals überhaupt von einer Lösung sprechen konnte. Leider tat er es nicht" ${ }^{“ 65}$ ).

Unter diesen epistemologischen Voraussetzungen kann Huguccio freilich kaum als Vertreter einer Lehre (oder gar Theorie) bezeichnet werden, so dass Stickler seine Kernthese, wonach Huguccio und andere Gelehrte des 12. Jahrhunderts zwei unterschiedliche materielle Schwerterbegriffe gekannt hätten, mit dieser Annahme ein Stück weit selbst desavouiert, wie schon Helmut G. Walther zu Recht monierte $\left.{ }^{66}\right)$.

Eine explizit formulierte Schwerterlehre im Sinne des gladius materialis ecclesiae ist also letztlich nicht nachzuweisen, auch nicht in der Zeit vor der von Stickler konstatierten Begriffsverwirrung. Stickler lieferte zwar in weiteren Einzeluntersuchungen auch für das 13. Jahrhundert Hinweise, dass bei einigen Kanonisten - will man nicht gravierende Widersprüche in Kauf nehmen - ein doppelsinniger Schwerterbegriff gebräuchlich war ${ }^{67}$ ), aber eine klare Distinktion, die angesichts der Bedeutung des Themas eigentlich zu erwarten wäre, findet sich auch bei diesen Gelehrten nicht. Der Hauptgrund dafür, dass sich im 12. Jahrhundert eine Schwerterlehre im Sinne Sticklers nicht ausbilden konnte, dürfte, wie bereits ausgeführt, in dem zu jener Zeit noch nicht voll entwickelten säkularen Eigenbewusstsein des Staates liegen, ohne das eine Unterscheidung in gladius materialis (= rein weltlichen Gewalt) und gladius materialis ecclesiae (= materielle Zwangsgewalt der Kirche) nicht sinnvoll eingeführt werden konnte ${ }^{68}$ ). Zudem hätte eine derartige Dopplung des materiellen Schwertes konsequenterweise aus der im 12. und

${ }^{63}$ ) Ansonsten, so betont Stickler unablässig, hätte sich Huggucio selbst „in grober Weise widersprochen“. Vgl. Stickler, Schwerterbegriff (oben Anm. 7) 232.

${ }^{64)}$ Vgl. Stickler ebd. 229ff.

${ }^{65)}$ Stickler ebd. 231.

66) Vgl. Walther (oben Anm. 58) 51.

${ }^{67}$ ) Vgl. Alfons M. Stickler, Der Dekretist Willielmus Vasco und seine Anschauungen über das Verhältnis der beiden Gewalten, Études d'histoire du droit canonique, Dédiées à Gabriel LeBras, Bd. 1 Paris 1965, S. 705-728.

${ }^{68}$ ) Die begriffliche und herrschaftstheoretische Verortung des ,Staats“ als eigenständige, von der Kirche unabhängige Ordnungskonfiguration ist im 12. Jahrhundert noch nicht hinreichend ausgeprägt gewesen, obgleich, so Walther (oben Anm. 58), die „Achtung vor einer eigenen Sphäre des ,Staates“, die Stickler bei allen Kanonisten 
13. Jahrhundert weit verbreiteten Zwei-Schwerter-Lehre eine Drei-Schwerter-Lehre gemacht, wie bereits Hoffmann kritisch bemerkte ${ }^{69}$ ). In einer Zeit, in der eine allegorische Bibelauslegung und die darauf basierenden Analogieschlüsse argumentativ einen hohen Stellenwert besaßen ${ }^{70}$ ), wäre eine explizit formulierte Lehre im Sinne des gladius materialis ecclesiae daher schwer zu vertreten gewesen. Schon Wilhelm Molitor hatte die von Fugger-Glött aufgestellte Behauptung zurückgewiesen, „dass das Mittelalter drei Schwerter in seiner officiellen Sprache kannte, nämlich das geistige [sic!] der Kirche, das zeitliche der Kirche und das zeitliche der Fürsten“" ${ }^{\text {“71 }}$ ), in dem er einen „Blick in das Decretalenrecht und in die Glosse und Commentare“ empfahl, wo die Anzahl der Schwerter ausdrücklich auf zwei festgelegt war $^{72}$ ). Gleichwohl räumte auch Molitor ein, dass die Terminologie bezüglich der Schwertgewalt

beobachtet, (...) ganz bestimmt als Anerkennung der Faktizität tief in ihrer Gedankenwelt verwurzelt [war]“ (S. 50).

${ }^{69)}$ Vgl. Hoffmann (oben Anm. 19) 80.

$\left.{ }^{70}\right)$ Vgl. Wilhelm Levison, Die mittelalterliche Lehre von den beiden Schwertern, in: DA 9 (1951) 14-42, S. $14 f$.

${ }^{71}$ ) Fugger-Glött (oben Anm. 20) S. 41. Dagegen Molitor (oben Anm. 4) 96ff. und Josef Berchtold, Die Bulle Unam Sanctam, Ihre wahre Bedeutung u. Tragweite f. Staat u. Kirche, München 1887, S. 70 Anm. 1.

${ }^{72}$ ) Glossa a. v. Nam dicentibus. Notandum ergo, quod si essent plures gladii, quam duo, non dixisset Dominus: Satis est, sed: parum est. Et si essent pauciores, non dixisset: Satis est, sed: nimis est. Ex ipsis itaque verbis Domini dicentis: Satis est - datur intelligi esse duos gladios in Ecclesia, non plures, nec pauciores, ed. Liber sextus decretalium D. Bonifacii Papae VIII., Extravag. Comm. lib. I. vol. 146, Venetiis 1605. Für das Verständnis der Schwertmetapher im 12. Jahrhundert ist die von Molitor angeführte Glosse „Nam dicentibus“ zur Bulle Unam Sanctam allerdings wenig aussagekräftig, und genau genommen ist damit auch Fugger-Glött in seiner Auslegung nicht widerlegt, denn dass es in ecclesia nur zwei Schwerter gibt, bestreitet auch er nicht. Das dritte Schwert, die rein zeitliche Gewalt der Fürsten, interessiere den Papst in seiner Bulle gar nicht, so Fugger-Glött, daher komme es in Unam Sanctam auch nicht vor. Mit einem vergleichbar schwachen argumentum e silencio erklärte auch Friedrich Kempf das Gewaltenverständnis Papst Gregors VII.: „Um die Verchristlichung der Welt ringend, führte er [Gregor] alle Lebensgebiete, auch das Königtum, auf ihre religiöse Funktion zurück und bezog sie damit in die von Rom geleitete Kirche ein, spiritualisierte sie. Daraus folgt jedoch nicht, daß er dem Königtum über seine Bindung an die Kirche hinaus eine eigene, von der Kirche unabhängige Wurzel habe bestreiten wollen. Wenn nicht alles täuscht, hat er sich diese Frage überhaupt nicht gestellt. Ihn interessierte nicht der Staat an sich ...", Friedrich Kempf, Weltherrschaft des mittelalterlichen Papsttums?, in: Stimmen der Zeit 158 (1955/56) 13-22, S. 17. Die Diskussion über die mögliche (und letztlich abgelehnte) Existenz eines dritten Schwertes bei Aegidius Romanus, De ecclesiastica potestate lib.2, c.13 steht in einem thematisch anderen Zusammenhang. 
im Mittelalter noch nicht „gehörig ausgebildet und festgestellt (war), woraus viele Zweideutigkeiten und Mißverständnisse entsprangen“"73).

Es bleibt letztlich ein Verdienst Sticklers, in seinen Forschungen auf die uneinheitliche und mitunter widersprüchliche Verwendung der (materiellen) Schwertmetapher in der hochmittelalterlichen Kanonistik hingewiesen zu haben - sein Versuch, diese Widersprüche mit Hilfe des gladius materialis ecclesiae aufzulösen, kann jedoch nicht in allen Punkten überzeugen.

\section{Der gladius materialis ecclesiae bei Francisco de Vitoria}

Mit der in der zweiten Hälfte des 13. Jahrhunderts einsetzenden Aristotelesrezeption gewann das weltliche Gemeinwesen eine eigenständige, naturrechtliche, von Kirche und Religion unabhängigere Grundlage, so dass auch eine rein weltliche Gewalt in herrschaftstheoretischen Überlegungen eine deutlichere Gestalt annehmen konnte ${ }^{74}$ ), wenngleich zentrale Gedanken und Begrifflichkeiten der früh- und hochmittelalterlichen sakralen Herrschaftsauffassung auch unter geänderten Vorzeichen in den herrschaftstheoretischen Diskurs des späten Mittelalters tradiert wurden ${ }^{75}$ ). In Folge der voranschreitenden Rationalisierung verlor zudem die allegorische Argumentation an Überzeugungskraft, was bisweilen zu polemischer Kritik an der Zwei-Schwerter-Lehre führ$t^{76}$ ), so dass sich die Frage stellt, ob der gladius materialis ecclesiae wenn

73) Molitor (oben Anm. 4) 97. Und selbst wenn man mit Stickler annehmen möchte, dass schon Gelehrte wie Bernhard von Clairvaux und Huguccio zwischen einem gladius materialis im Sinne der rein weltlichen Gewalt und einem gladius materialis ecclesiae im Sinne der kirchlich-materiellen Zwangsgewalt unterschieden haben, so ist doch offensichtlich, dass sie dann uneins darüber waren, welches der beiden Schwerter in Luk 22,38 neben dem gladius spiritualis symbolisiert wird. Nach Ansicht von Stickler und Kennan (oben Anm. 13) sah Bernhard in Luk 22,38 geistliche und materielle Zwangsgewalt der Kirche allegorisiert, während Huguccio das ecce duo gladii eindeutig zur Unterscheidung von geistlicher und weltlicher (staatlicher) Gewalt anführt.

${ }^{74}$ ) Zur herrschaftstheoretischen Bedeutung der Aristotelesrezeption vgl. Tilman Struve, Die Bedeutung der aristotelischen „Politik“ für die natürliche Begründung der staatlichen Gemeinschaft, in: Albert Zimmermann (Hg.), Soziale Ordnungen im Selbstverständnis des Mittelalters, Berlin 1980, S. 144-161; vgl. aber auch J o seph P. Canning, Ideas of the State in Thirteenth and Fourteenth-Century Commentators on the Roman Law, in: Transactions of the Royal Historical Society 33 (1983) 1-27, der die Bedeutung des Römischen Rechts für die Entwicklung eines spätmittelalterlichen Staatsverständnisses hervorhebt.

${ }^{75)}$ Vgl. Kosuch (oben Anm. 56).

${ }^{76}$ ) Zur spätmittelalterlichen Kritik an der Zwei-Schwerter-Lehre vgl. Wilhelm 
schon nicht im 12. Jahrhundert, so doch später tatsächlich in Abgrenzung zur rein weltlichen (Staats-)Gewalt entwickelt wurde. Ullmann und Hoffmann hatten ihre Kritik an Sticklers Thesen explizit nur für das Hochmittelalter formuliert und bemängelt, es würden spätere Theorien über das Verhältnis von Kirche und Staat in anachronistischer Weise in die Quellen des 12. Jahrhunderts hineingelesen. Und auch Wilhelm Molitor hatte schon Ende des 19. Jahrhunderts zugegeben, dass dem von Fugger-Glött unternommenen Interpretationsversuch mit den drei Schwertern bei aller Kritik ja durchaus „ein Gedanke zu Grunde liege, welcher an und für sich eine Wahrheit enthält: der Gedanke nemlich [sic!], daß der Kirchengewalt ein gewisser Wirkungskreis in weltlichen Dingen nicht abgesprochen werden könne, nichtsdestoweniger aber die eigentliche weltliche Gewalt selbstständig sei und nicht von der Kirche im eigentlichen Sinne übertragen werde ${ }^{\text {“77 }}$ ).

Während die herrschaftstheoretische Verortung einer rein zeitlichen (Staats-)Gewalt in hochmittelalterlichen Quellen zumindest problematisch erscheint, besteht für die meisten Gelehrten des 16. Jahrhunderts kein Zweifel mehr darüber, dass jedem zeitlichen Gemeinwesen eine eigene, naturrechtliche Lenkungsgewalt zukomme. Auch der Begründer der spanischen Spätscholastik, Francisco de Vitoria, kennt eine derartige Gewalt in den Händen der Fürsten. Diese Gewalt werde den Fürsten von Gott (Wirkursache) und dem Volk (Materialursache) übertragen mit dem Ziel, das in sich vollkommene und abgeschlossene zeitliche Gemeinwesen zu regieren ${ }^{78}$ ). In dieser Hinsicht seien die Fürsten und Könige dem Papst in keiner Weise untertan. Neben dieser rein zeitlichen Gewalt der Fürsten und Könige kennt Vitoria aber auch eine zeitliche Gewalt der Kirche, die ihr auf der ganzen Welt zukomme $^{79}$ ). Auch die Kirche sei eine societas perfecta, und als solcher müsse ihr zum Erreichen ihres geistlichen Endziels gegebenenfalls eine eigene zeitliche Zwangsgewalt zur Verfügung stehen. Diese zeitliche Gewalt der Kirche könne jedoch nur dann in Anspruch genommen werden, wenn es sich nicht

Levison (oben Anm. 70) 39f.; Arno Borst, Der mittelalterliche Streit um das weltliche und das geistliche Schwert, in: Walther Peter Fuchs (Hg.), Staat und Kirche im Wandel der Jahrhunderte, Stuttgart 1966, S. 34-52, S. 49ff. Kritik an der allegorischen Auslegung von Luk 22,38 wurde aber schon vom Yorker Anonymus (um 1100) geübt, vgl. Levis on (oben Anm. 70) 31f.

${ }^{77}$ ) Molitor (oben Anm. 4) 97.

${ }^{78}$ ) Francisco de Vitoria, Vorlesungen I-II (Relectiones), Völkerrecht, Politik, Kirche, Stuttgart 1995-1997, hier I S. 238: Res publica temporalis est res publica perfecta et integra. Vgl. den Traktat De potestate civili, ebd. S. 114-161.

${ }^{79}$ ) de Vitoria (oben Anm. 78) I 246: In ecclesia est aliqua potestas et auctoritas temporalis in toto orbe. 
um rein zeitliche Angelegenheiten handelt, sondern um zeitliche Angelegenheiten, die auch in Beziehung zum geistlichen Endziel stehen.

„Dass es in der Kirche eine zeitliche Gewalt gibt, die auf die geistliche Gewalt bezogen ist, wird erstens bewiesen, weil das Zeitliche, wie oben ausgeführt, in einer Weise notwendig und auf den geistlichen Zweck bezogen ist. Wenn Christus also keine Gewalt zurückgelassen hätte, deren Aufgabe es ist, bei Bedarf Anordnungen zu treffen und vom Zeitlichen in einer dem geistlichen Zweck angemessenen Weise Gebrauch zu machen, hätte er nicht hinreichend für die geistlichen Belange Sorge getragen und vorgesorgt. Diese Aufgabe fällt aber nicht den weltlichen Herrschern zu, die das Verhältnis vom Zeitlichen zum Geistlichen nicht kennen und für die geistlichen Belange keine Verantwortung tragen. Also ist es Aufgabe der kirchlichen Gewalt, vom Zeitlichen im Blick auf das Geistliche Gebrauch zu machen. Falls es also für die Wahrung oder Ausrichtung geistlicher Belange einmal notwendig sein sollte, Zeitliches, das materielle Schwert und zeitliche Vollmacht, in Anspruch zu nehmen, dann wird der Papst dies können“ ${ }^{80}$ ).

Ein eigenständiges Tätigwerden der weltlichen Fürsten mit ihrer rein zeitlichen Gewalt ist in solchen Angelegenheiten also nicht statthaft. Eine genuine Verantwortung der weltlichen Gewalt für kirchlich-religiöse Belange, so wie sie Stickler z. B. bei Gratian und Huguccio herauslesen möchte ${ }^{81}$ ), und wie sie in der frühneuzeitlichen cura religionis der (protestantischen) Fürsten wirksam wurde, lehnt Vitoria unmissverständlich ab. Zur Führung des kirchlichen gladius materialis werden aber auch nach Ansicht von Vitoria idealerweise die weltlichen Fürsten herangezogen, wobei es in der zitierten Passage aus der ersten Vorlesung De potestate ecclesiae unklar bleibt, ob dieses materielle Schwert nun das (rein zeitliche) Schwert der Fürsten ist, dessen Gebrauch ihnen der Papst in bestimmten Fällen eben doch (gewissermaßen auf Kosten der staatlichen Souveränität) vorschreiben kann, oder ob es sich um einen separaten gladius materialis ecclesiae handelt. Letztere Interpretation wird durch eine aufschlussreiche Passage aus Vitorias fragmentarischer Schrift De regno Christi nahegelegt. Gestützt auf Thomas von Aquin lehnt Vitoria auch

${ }^{80}$ ) de Vitoria (oben Anm. 78) I 248: Et primo, quod in ecclesia sit potestas temporalis in ordine ad finem spiritualem, probatur, quia temporalia, ut supra dictum est, aliquo modo sunt necessaria et ordinata ad finem spiritualem. Ergo Christus non satis providisset et cavisset rebus spiritualibus, si non reliquisset aliquam potestatem, ad quam spectaret, quando opus esset ordninare et uti temporalibus convenienter ad finem spiritualem. Sed hoc non spectat ad officium principum saecularium, qui ignorant proportionem rerum temporalium ad spiritualia nec habent curam rerum spiritualium. Ergo ista cura utendi temporalibus ad spiritualia est potestas ecclesiasticae. Ergo si necessarium sit aliquando ad conservationem aut administrationem rerum spiritualium uti temporalibus et materiali gladio et auctoritate temporali, papa hoc poterit.

$\left.{ }^{81}\right)$ Vgl. oben Anm. 43. 
in diesem Werk eine rein zeitliche Gewalt des Papstes ab. Eine solche könne aus dem Königtum Christi nicht geschlussfolgert werden, wohl aber

„... eine (zeitliche) Herrschaftsgewalt von der Art, wie sie (die Päpste) in der ganzen Welt haben, nämlich insofern es für das geistliche Reich der Seelen erforderlich ist. (...) Und doch spricht Thomas im ganzen dritten Teil [der Summa theologica], in dem er doch vom Thema her über Christus spricht, niemals über andere zeitliche Gewalt Christi. Alle anderen Irrmeinungen müssen also gänzlich fallengelassen werden. Ja, ich glaube, dass der heilige Thomas, als er jenen dritten Teil verfasste, der Vorstellung anhing, dass die Kaiser Stellvertreter Christi im zeitlichen Bereich gewesen seien, wiewohl er dies auch in dem kleinen Werk ,Über die Regierung der Herrscher` zum Ausdruck gebracht hat. Dort sagt er auch, dass alle diejenigen Tyrannen gewesen seien, die ihre Befehlsgewalt nicht mit Zustimmung der römischen Kirche bekommen hätten. Nach meiner Meinung ist diese Aussage aber nicht wegen der zeitlichen Gewalt im eigentlichen Sinne zutreffend, sondern deswegen, (...) weil dem Papst im Hinblick auf das geistliche Regiment manchmal zeitliche Herrschaftsgewalt im außerordentlichen Sinne zukommt. Dennoch macht man entweder die Aussage, dass die Kaiser und Könige Stellvertreter Christi und seiner Nachfolger in dem besagten Sinne waren, oder man sagt, dass sie Christus unterstanden, weil Christus als Messias und dem Papst als dessen Stellvertreter die Vollmacht verliehen wurde, von den zeitlichen Dingen und Königtümern Gebrauch zu machen, insoweit die für den eigenen Zweck und das eigene Amt erforderlich ist, nämlich die Leitung der Kirche. Somit hätten Christus und der Papst gewisse Macht über Könige und Kaiser. Aber ich glaube nicht, dass diese Herrscher ihre rein zeitliche Gewalt vom Papst haben“(82).

Ersetzt man den Ausdruck potestas temporalis durch gladius materialis ${ }^{83}$ ), dann kommt man Sticklers Theorie sehr nahe. Der gladius materialis ecclesiae wird demnach von den Kaisern und Königen im Dienste und Auftrag des

${ }^{82}$ ) de Vitoria (oben Anm.78), II 698: ... sed eo modo, quo habent in toto mundo, quantum scilicet requiritur ad regnum spirituale animarum. (...) Nec in tota tertia parte unquam loquitur de alia potestate temporali Christi, ubi tamen ex proposito loquitur de Christo. Sunt ergo omnia omnino dimittenda alia somnia. Immo ego credo, quod quando sanctus Thomas scripsit tertiam partem, erat illius phantasiae, quod imperatores erant vicarii Christi quantum ad temporalia, licet hoc dixerit in opusculo De regimine principum, ubi etiam dicit, quod omnes, qui non habuerunt imperium ex consensu ecclesiae Romanae, fuerunt tyranni. Hoc autem puto non verum esse propter potestatem temporalem proprie, sed (...) quia ad papam ratione regiminis spiritualis pertinet aliquando dominium temporale exordinarie. Tamen vel dicitur, quod imperatores et reges erant vicarii Christi et successorum eius ad hunc sensum, vel erant sub eo, quia Christo inquantum Messias et papae inquantum vicario eius data est potestas utendi temporalibus et regnis, quantum est necessarium ad suum finem et officium, scilicet ad gubernationem Ecclesiae. Et sic haberent aliquam potestatem supra reges et imperatores. Sed non puto, quod meram potestatem temporalem habeant a papa.

${ }^{83}$ ) So wie es Vitoria in De potestate ecclesiae I. tut, vgl. Anm. 80. 
Papstes geführt, die darin gleichsam vicarii Christi / papae in temporalibus sind. In der Ausübung der rein zeitlichen (Staats-)Gewalt sind die Kaiser und Könige hingegen vom Papst unabhängig, da sie diese Gewalt von Gott und dem Volk qua Naturrecht übertragen bekommen haben, Christus jedoch eine solche Gewalt abgelehnt habe und daher auch der Papst keine solche rein zeitliche Gewalt besitze. Staatsgewalt und zeitliche Gewalt der Kirche sind demnach verschiedene Gewalten mit unterschiedlichem herrschaftstheoretischem Ursprung.

In seiner ersten Vorlesung über die kirchliche Gewalt gibt Vitoria gleichwohl zu verstehen, dass die zeitliche Gewalt der Kirche eigentlich eine Konsequenz der potestas spiritualis sei, womit er einen Kerngedanken jener Lehre vertritt, die zu Beginn des 17. Jahrhunderts in Robert Bellarmin und Francisco Suarez ihre prominentesten Vertreter haben wird und gemeinhin mit dem Begriff der potestas indirecta charakterisiert wird ${ }^{84}$ ). In rein zeitlichen Angelegenheiten, so Vitoria, könne der Papst zwar nicht in den Herrschaftsbereich der weltlichen Fürsten eingreifen, wohl aber, wenn die zeitlichen Angelegenheiten in Beziehung zum geistlichen Endziel stünden, wobei das päpstliche Eingreifen dann ,nicht aufgrund der zeitlichen Gewalt, sondern aufgrund der geistlichen Gewalt" geschehe ${ }^{85}$ ).

Mochte die zeitliche Gewalt der Kirche im Idealfall, d. h. bei Einvernehmen zwischen Papst und weltlichem Fürsten, über die Autorität der geistlichen Gewalt gleichsam als potestas indirecta in temporalibus umgesetzt werden, so steht der Kirche jedoch im Notfall, d.h. bei Verweigerung des weltlichen Fürsten, auch ein eigener gladius materialis zur Verfügung. Ausdrücklich heißt es bei Vitoria zum gladius materialis:

$\left.{ }^{84}\right) \mathrm{Zu}$ Bellarmin vgl. Franz Xaver Arnold, Die Staatslehre des Kardinals Bellarmin, Ein Beitrag zur Rechts- und Staatsphilosophie des konfessionellen Zeitalters, München 1934; John Courtney Murray, St. Robert Bellarmine on the Indirect Power, in: Theological Studies 9 (1948) 491-535; und Stefania Tutino, Empire of souls, Robert Bellarmine and the Christian commonwealth, Oxford 2010; zu Suarez vgl. Heinrich A. Rommen, Die Staatslehre des Franz Suarez S.J., Gladbach 1926; Francis P. Canavan, Subordination of the State to the Church according to Suarez, in: Theological Studies 12 (1951) 354-364; und Dominik Recknagel, Einheit des Denkens trotz konfessioneller Spaltung, Parallelen zwischen den Rechtslehren von Francisco Suárez und Hugo Grotius, Frankfurt am Main 2010.

${ }^{85}$ ) de Vitoria (oben Anm. 78) I 238ff.: Ego vero dico ipsum [papam] nec habere usum potestatem [temporalem] et ideo nec ad ipsum spectare iudicium causarum temporalium nec in prima instantia nec in gradu appellationis. (...) Non enim nego, quin in casu possit haberi recursos ad papam et quod ipse possit rescindere iudicium civile - sed hoc non ratione potestatis temporalis, sed ratione spiritualis praecise. 
„Aber damit dies noch deutlicher werde, wird gefragt: Besteht diese zeitliche Gewalt, über die der höchste Priester verfügt, nur durch Vermittlung der geistlichen Gewalt und des geistlichen Schwerts, oder kann der Papst kraft seiner zeitlichen Gewalt eine entsprechende Handlung vollziehen? Kann der Papst beispielsweise, wenn es zur Verteidigung des Glaubens notwendig ist, dass die Spanier gegen die Sarazenen in den Krieg ziehen, lediglich den [spanischen] König mit Rügen und Vorschriften dazu zwingen, dass die Spanier in den Krieg ziehen? Oder kann der Papst selbst kraft eigener Bevollmächtigung den Krieg erklären und die Spanier zu den Waffen rufen, die dann dazu verpflichtet wären, ihm wie dem König Folge zu leisten“"86)?

Vitorias Antwort: Der Papst habe zunächst im Sinne der potestas indirecta von seiner potestas spiritualis Gebrauch zu machen und müsse den spanischen König auffordern, mit seiner (rein weltlichen) Gewalt im Interesse der Kirche tätig zu werden. Sollte der König sich jedoch weigern, dieser christlichen Herrscherpflicht nachzukommen, dann könne der Papst „kraft eigener Autorität“ (auctoritate papae) den christlichen Glauben durch seinen eigenen gladius materialis verteidigen ${ }^{87}$ ).

Offenkundig war sich Vitoria der Problematik und Verwechslungsgefahr zwischen der rein zeitlichen Gewalt der Fürsten einerseits und der zeitlichen Gewalt der Kirche andererseits vollauf bewusst, denn wiederholt kritisierte er die hierokratische Lehre als Produkt eben einer solchen Begriffsverwirrung, wie sie Stickler in seinen Arbeiten konstatierte $\left.{ }^{88}\right)$. Die Schuld dafür liege insbesondere bei den glossatores iuris (...) cum ipse essent pauperes rebus et doctrina, da sie die rein zeitliche Staatsgewalt und die zeitliche Gewalt der Kirche durcheinander bringen würden ${ }^{89}$ ). Vitoria hat in diesem Zusammenhang auch die Zwei-Schwerter-Lehre als Problem erkannt. Die Unterscheidung zwischen einer von Gott und Volk auf naturrechtlichem Wege übertragenen staatlichen Gewalt sowie einer zeitlichen Gewalt der Kirche (die bei Vitoria ausdrücklich nicht bloß die indirekte Folge der geistlichen Gewalt ist $^{90}$ )) kann im Rahmen der Zwei-Schwerter-Lehre nicht adäquat transportiert

${ }^{86}$ ) de Vitoria I 248: Sed ut magis exponantur, dubitatur, utrum haec potestas temporalis in summo pontifice intelligatur solum mediante potestate et gladio spirituali an immediate exercere possit potestatis temporalis actum. Exempli gratia, si pro defensione fidei necesse est, ut Hispani profiscantur ad bellum adversus Saracenos, utrum papa solum possit censuris et praeceptis cogere regem, ut profiscantur Hispani ad bellum, an ipse indicere bellum propria auctoritate et vocare Hispanos in bellum et quod teneantur eum sequi sicut regem.

${ }^{87}$ ) de Vitoria ebd. I $250 \mathrm{ff}$.

${ }^{88}$ ) So der Tenor der gesamten Quaestio V. De potestate ecclesiae I., vgl. de Vitoria (oben Anm.78), I 228-262.

${ }^{89}$ ) de Vitoria (oben Anm. 78) I 236.

${ }^{90}$ ) Vgl. oben Anm. 86. Insofern ist die ausschließlich auf die potestas indirecta 
werden, da in der Allegorie neben dem geistlichen Schwert eben nur Platz für ein gladius materialis ist. Überhaupt lehnt Vitoria selbst eine Auslegung von Luk 22,38 in sensu litterali ab.

„Was die beiden Schwerter angeht, so ist deutlich, dass hier nichts im wörtlichen Sinne gemeint ist. Vielmehr war es so, dass die Apostel, als Christus ihnen deutlich gemacht hatte, dass ihnen Widerspruch entgegengebracht werden werde und sie sich würden verteidigen müssen, irrtümlicherweise sagten: ,Siehe, hier sind zwei Schwerter" usw. “91).

Freilich weiß Vitoria um die große Bedeutung, die dieser Lehre in der theologischen und vor allem kanonistischen Tradition sowie in der hierokratischen Argumentation zukommt.

„Ferner leiten jene Leute [die Hierokraten] aus jenem Satz Luk 22,38 ein Argument ab: ,Hier sind zwei Schwerter‘. Dazu siehe die Ientacula von Cajetan. Diesen Satz bezieht [Papst] Bonifaz [VIII.] im extravaganten Dekretale auf das geistliche und das zeitliche Schwert, ebenso Bernhard [von Clairvaux] in seiner Schrift an [Papst] Eugen [III.]“92).

Vitoria jedoch sieht in den beiden Schwertern keine Allegorie für die zeitliche Gewalt der Fürsten und die geistliche Gewalt des Papstes, sondern wenn überhaupt, dann für die geistliche und materielle Zwangsgewalt der Kirche. Die Zwei-Schwerter-Lehre würde auch bei Bonifaz VIII. und Bernhard von Clairvaux letztlich „nicht mehr beweisen, als von uns behauptet, nämlich dass der höchste Priester von Fall zu Fall alle jene [zeitlichen Zwangs-] Maßnahmen durchführen kann, und zwar dann, wenn sie zur Beseitigung einer Anstößigkeit in der Herrschaft, für den Schutz der Religion gegen die Heiden oder dergleichen ähnliches erforderlich ist" ${ }^{\text {“93 }}$ ).

Vitoria versucht also, die Zwei-Schwerter-Lehre aus seiner Argumentation weitgehend auszublenden, um einer Begriffsverwirrung von rein zeitlicher Staatsgewalt und materieller Zwangsgewalt der Kirche nicht Vorschub zu leisten. Er sieht die materielle Zwangsgewalt der Kirche im Idealfall (bei Einvernehmen zwischen Staat und Kirche) gleichsam indirekt über die Hilfe des Staates gewährleistet, im Notfall jedoch (bei Verweigerung der staatlichen

ausgelegte Interpretation durch J osef Biederlack, Das Verhältnis von Kirche und Staat bei Franz von Vitoria O. P., in: Zeitschrift für katholische Theologie 51 (1927) 548-555 zu korrigieren.

${ }^{91}$ ) de Vitoria (oben Anm. 78) I 262.

$\left.{ }^{92}\right)$ de Vitoria ebd. I 260.

${ }^{93}$ ) Ebd. Die rein zeitliche (Staats-)Gewalt der Fürsten hingegen wird von Vitoria in seinem gesamten Werk lediglich einmal im Traktat De homicidio mit der Schwertmetapher in Verbindung gebracht, als das Tötungsrecht des Herrschers mit Röm 13,4 bewiesen wird. De Vitoria (oben Anm. 78) I 474. 
Unterstützung) verfüge die Kirche sehr wohl über einen eigenen, von Christus verliehenen gladius materialis.

Eine ähnliche Position vertritt auch der spanische Theologie Luis de Molina Ende des 16. Jahrhunderts in seinem Werk De Iustitia et Iure. Wann immer es das geistliche Endziel erfordere, könne der Papst notfalls Könige absetzen, in die weltliche Gesetzgebung eingreifen und in zeitlichen Angelegenheiten urteilen, und zwar nicht nur aufgrund von geistlichen Vorschriften, sondern mit Zwangs- und Waffengewalt, ganz wie jeder andere weltliche Herrscher, wenngleich es auch nach Ansicht Molinas zweckmäßiger sei, dass diese zeitlichen Zwangsmaßnahmen nicht vom Papst selbst, sondern durch einen weltlichen Fürsten umgesetzt würden ${ }^{94}$ ). Die Problematik, wie diese päpstliche Gewalt im Zeitlichen neben der naturrechtlichen Staatsgewalt und der geistlichen Gewalt des Papstes begrifflich zu verorten ist, wird bei Molina besonders deutlich, da er sich (anders als Vitoria) in diesem Zusammenhang der Zwei-Schwerter Allegorie bedient:

„Und aus diesem Grund wird gesagt, dass der Papst beide Schwerter, die höchste zeitliche und geistliche Gewalt, besitzt. Man beachte jedoch, dass diese höchste zeitliche Jurisdiktionsgewalt des Papstes, da sie nicht auf das Zeitliche selbst, sondern auf das übernatürliche Ziel hingeordnet ist, keine rein zeitliche Gewalt, sondern eine geistliche Gewalt ist. Um diese spezielle Gewalt von der rein geistlichen Gewalt, die mit dieser verbunden ist, zu unterscheiden, sollte sie aber nicht als weltliche Gewalt, sondern als kirchliche Gewalt mit zeitlicher Jurisdiktion bezeichnet werden" ${ }^{\text {(95)}) . ~}$

Neben der naturrechtlichen Staatsgewalt, die ausschließlich auf das rein Zeitliche ausgerichtet ist, und der rein geistlichen Gewalt des Papstes existiert

${ }^{94}$ ) Luis de Molina, De Iustitia et Iure, Vol. 1, Moguntiae 1614, II, 29, 143E-144A: Quare, si id exigat finis supernaturalis, potest Summus Pontifex deponere reges, eosque regnis suis privare. Potest leges infirmare, et reliqua omnia inter Christianos omnes exequi, quae ad supernaturalem finem salutemque communem spiritualem, non utcumque, sed simpliciter prudentis arbitrio judicata fuerint necessaria, idque non solum censuris ad id cogendo, sed etiam poenis externis, ac vi, et armis, non secus, ac quivis alius princeps secularis. Tametsi ut plurimum expediens sit Summum Pontificem non per se, sed per principes seculares id exequi. Vgl. Frank B. Costello, The political philosophy of Luis de Molina, S.J. 1535-1600, Rom 1974, S. 88ff.

${ }^{95}$ ) de Molina (oben Anm. 94) II, 29, 144A: Atque hac ratione vere Summus Pontifex dicitur habere utrumque gladium, supremamque potestatem temporalem et spiritualem. Observa tamen, supremam hanc potestatem jurisdictionis temporalis, quae in Summo Pontifice residet, cum non ad temporalia ipsa, sed ad supernaturalem finem ordinetur, non esse mere potestate temporalem, sed esse spiritualem ex parte finis. Quo fit, ut appellanda non sit potestas laica, sed Ecclesiastica, jurisdictionis tamen temporalis, ut illam distinguamus a potestate mere spirituali, quae illam annexa habet. 
also gleichsam als drittes die zeitliche Gewalt des Papstes, die der potestas spiritualis gewissermaßen inhärent, wenn auch nicht mit ihr identisch ist ${ }^{96}$ ). Während Vitoria dem Papst jenseits der potestas spiritualis einen eigenen gladius materialis zugesteht, versucht Molina die päpstliche Gewalt im Zeitlichen als Teil der potestas spiritualis zu verorten. Mit der Zwei-SchwerterAllegorie lässt sich dieser Gedankengang, der im Zentrum der frühneuzeitlichen Lehre von der päpstlichen potestas indirecta steht, jedoch nur schwer versinnbildlichen.

\section{Zwei-Schwerter-Lehre und potestas indirecta}

Die frühneuzeitliche Entwicklung der Gewaltendiskussion wurde im Wesentlichen von der Lehre der potestas indirecta bestimmt, die untrennbar mit den Namen Robert Bellarmin und Francisco Suarez verknüpft ist, wenngleich wie gesehen einige Gedanken und Begrifflichkeiten dieser Lehre schon von früheren Autoren aufgebracht worden waren ${ }^{97}$ ). Der Kern der Lehre darf darin gesehen werden, dass der Papst ausschließlich eine geistliche Gewalt besitzt, über die er aber, sofern Fragen des Seelenheils betroffen sind, auch im materiell-zeitlichen Bereich weitreichenden Einfluss nehmen kann ${ }^{98}$ ). Zwar wolle,

${ }^{96}$ ) Die Übersetzung von utrumque gladium durch Costello (oben Anm. 94) 89 mit „zweischneidiges Schwert“ (double-edged sword) ist sicherlich falsch, wenngleich mit dieser Formulierung, hätte Molina sie gewählt, der komplizierte Sachverhalt treffender hätte umschrieben werden können. Anstatt dem Papst zwei Schwerter zuzuschreiben, wodurch - aufgrund der unumstößlichen Zweizahl der Schwerterallegorie - kein Platz für ein weiteres königlich/kaiserliches Schwert mehr ist, würde der Papst nur ein Schwert besitzen, dessen Kompetenzen sowohl in geistlichen wie auch in zeitlichen Angelegenheiten durch die zwei Schneiden zum Ausdruck käme. Das zweite Schwert könnte so problemlos auf die rein zeitliche Staatsgewalt bezogen werden.

${ }^{97}$ ) Vgl. Franz Gillmann, Von wem stammen die Ausdrücke „potestas directa“ und „potestas indirecta“ papae in temporalia?, in: Archiv für katholisches Kirchenrecht 98 (1918) 407-409; Ralph Kuiters, Was bedeuten die Ausdrücke „directa“ und ,indirecta potestas“ papae in temporalibus bei Ägidius von Rom, (Jakobus von Viterbo) und Johannes von Paris?, in: Archiv für katholisches Kirchenrecht 128 (1957) 99-105.

${ }^{98}$ ) Zur Lehre der potestas indirecta vgl. als Überblick Harro Höpfl, Jesuit political thought, The Society of Jesus and the state, c. 1540-1630, Cambridge 2004, S. 339-365. Noch zu Beginn des 20. Jahrhunderts wies der jesuitische Generalobere Franz Xaver Wernz in seinem Ius decretalium ausdrücklich darauf hin, dass der Staat in den res mixtae der Kirche aufgrund der päpstlichen potestas indirecta untergeordnet sei, einer Gewalt, die ,an sich keine zeitliche (politische), sondern eine geistliche ist, wenn sie sich auch wegen der geistlichen Interessen auf weltliche Dinge bezieht“. Zitiert nach Reginald Schultes, Die Autorität der Kirche in weltlichen Dingen, Mainz 1912, S. 19. In der Literatur wird immer wieder zu Recht darauf hingewiesen, 
so Bellarmin, kein Theologe ernsthaft bestreiten, dass der Papst die höchste Gewalt über Geistliches und Körperliches habe,

„... aber die Frage ist, ob der Papst eine Gewalt hat, die vorzugsweise eine geistliche ist und so hoch über allen zeitlichen Gewalten steht, dass er damit in allen zeitlichen Angelegenheiten, die auf das Geistliche hingeordnet sind, Anordnungen treffen kann; oder ob er zwei unterschiedliche Gewalten hat, die eine geistlich, die andere zeitlich, beide aus göttlichem Recht, so dass der Heilige Petrus von Christus sowohl zum höchsten Bischof als auch zum höchsten König des Erdkreises ernannt worden ist“ [Sperrung A.K.]99).

Letzteres war die hierokratische Position, die wie schon von Vitoria, so auch von Bellarmin scharf zurückgewiesen wurde ${ }^{100}$ ). Statt dessen, so Bellarmin weiter,

dass die Lehre der potestas indirecta nicht das Verhältnis zwischen Kirche und Staat per se regelt, sondern nur zwischen katholischer Kirche und katholischen Staatswesen, vgl. Jakob Gemmel, Die Lehre des Kardinals Bellarmin über Kirche und Staat, in: Scholastik 5 (1930) 357-379, S. 371ff.; J ohann Kleinhappl, Der Staat bei Ludwig Molina, Innsbruck 1935, S. 150f.; Kempf, Katholische Lehre (oben Anm. 32) 62. Heidnische Staaten haben (so schon Thomas von Aquin) eine legitime, naturrechtlich begründete Herrschaft, auf die der Papst nicht Einfluss nehmen kann. Bei katholischen Staatswesen jedoch greift das Prinzip der Überordnung. Der katholische Fürst erhält seine Gewalt zwar ebenfalls auf naturrechtlichem Wege, stellt diese Gewalt jedoch aufgrund der von ihm als Katholiken anerkannten Superiorität des Papstes ggf. in den Dienst der Kirche. Kritiker bemängelten, dass der katholische Fürst letztlich weniger Souveränität besitze als ein heidnischer Fürst (vgl. auch unten Anm. 127); in den Augen der Kirche freilich bedeutete diese Unterordnung eine qualitative Aufwertung der naturrechtlichen Staatsgewalt, die nun in den Dienst der Wahrheit gestellt werde, so etwa schon Jakob von Viterbo im 14. Jahrhundert, vgl. Kosuch (oben Anm. 56) 165ff. Zu der damit verbundenen Problematik, ob und inwieweit sich - gemäß der Logik der potestas indirecta - durch die Taufe eines heidnischen Fürsten auch die Natur seiner Herrschaftsgewalt verändern müsse, vgl. die kontroversen Ansichten von Höpfl a.a. O. 364, Canavan (oben Anm. 84) 357 und Murray (oben Anm. 84) 500.

${ }^{99}$ ) Auctarium Bellarminianum, Supplément aux Oeuvres du Cardinal Bellarmin, Paris 1913, S. 433: Sed quaestio est de modo, utrum videlicet Summus Pontifex habeat unam potestatem, eamque proprie spiritualem, quae ita supra potestates omnes temporales emineat, ut per eam possit de temporalibus omnibus disponere, in ordine ad spiritualia; an vero duas distinctas habeat potestates, unam spiritualem, alteram temporalem, utramque jure divino, ita ut B. Petrus simul fuerit a Christo Summus Pontifex, et summus rex orbis terrarum institutus.

${ }^{100}$ ) Diese Ablehnung einer expliziten päpstlichen potestas temporalis war der Hauptgrund, warum das Werk Bellarmins auf den Index gesetzt werden sollte. Vitoria hatte zwar ebenfalls die Hierokratie entschieden abgelehnt, dem Papst aber mit dem gladius materialis ecclesiae auf anderem Wege eine eigene Gewalt im Zeitlichen zugestanden. 
kommt dem Papst in erster Line das Geistliche an sich zu, da seine eigentliche Gewalt eine geistliche ist. Das Zeitliche hingegen kommt ihm erst in zweiter Hinsicht und gleichsam folgerichtig zu und sollte daher indirekte Gewalt genannt werden“" $\left.{ }^{101}\right)$.

Bellarmin warnte also ausdrücklich davor, den päpstlichen Einfluss im zeitlichen Bereich als Konsequenz einer päpstlichen potestas temporalis zu bezeichnen, da er lediglich indirecte aus der päpstlichen potestas spiritualis resultiere. Doch wurde gerade dieser wichtige Aspekt in den kommenden Jahrhunderten nicht zuletzt durch das fortwährende Festhalten an der ZweiSchwerter-Allegorie oft von Theologen wie Kanonisten gleichermaßen verkannt $^{102}$ ). Schon bei Bellarmin und Suarez - die beide versuchten, die Lehre der potestas indirecta „mit überkommenen Symbolen und Beweisen zu stützen“, und bemüht waren, „von den bisherigen Argumenten soviel zu retten, als es möglich war“103) - erwies sich der Rekurs auf die Zwei-Schwerter-Lehre als problematisch und irreführend.

Auch Bellarmin und Suarez erkannten selbstverständlich eine naturrechtlich begründete Staatsgewalt an, die der weltliche Fürst von Gott und Volk verliehen bekomme, um das weltliche Gemeinwesen zu regieren ${ }^{104}$ ). Diese staatliche Gewalt sei grundsätzlich und prinzipiell zu trennen von der geistlichen Gewalt des Papstes, ebenso grundsätzlich aber stehe dessen geistliche Gewalt über der staatlichen Gewalt $\left.{ }^{105}\right)$. Wiederholt greifen Bellarmin und Suarez zur Verdeutlichung dieser Überordnung auf die traditionsreiche Zwei-Schwerter-Lehre zurück und sprechen der Kirche beide Schwerter zu, wobei das materielle Schwert in ihrer Auslegung dasjenige der weltlichen Fürsten ist, über das der Papst kraft seiner geistlichen Gewalt verfügen kann, sofern das geistliche Ziel betroffen ist. So heißt es etwa bei Bellarmin:

${ }^{101}$ ) Auctarium Bellarminianum (oben Anm. 99) 433 : ... spiritualia per se et primo ad Pontificem, cujus potestas proprie spiritualis est, pertinere; temporalia vero secundario et consequenter, quod etiam indirecte dici solet. Vgl. Gemmel (oben Anm. 98) 365.

$\left.{ }^{102}\right)$ Vgl. Alexander Dordett, Die kirchliche Straf- und Zwangsgewalt bei Bellarmin und Suarez, Louvain 1952, S. 24ff. Auch Tutino (oben Anm. 84) weist S. 43 darauf hin, wie bereits Suarez und Molina im Gegensatz zu Bellarmin das päpstliche Eingreifen in zeitlichen Angelegenheiten als „quasi-temporal power“ charakterisieren.

${ }^{103}$ ) Dordett (oben Anm. 102) 18.

104) Vgl. den zusammenfassenden Überblick bei Höpfl (oben Anm. 98) 186-223.

${ }^{105}$ ) Vgl. Roberto Bellarmino, Tractatus de Potestate Summi Pontificis In Rebus Temporalibus, Adversus Gulielmum Barclaium, Coloniae Agrippinae 1610, c. 2, S. 41 . 
„So wie die Kirche sich aus geistlichen und weltlichen Fürsten zusammensetzt, die gleichsam die zwei Arme der Kirche sind, so hat sie auch zwei Schwerter, ein geistliches und ein materielles, und wenn es die rechte Hand mit dem geistlichen Schwert nicht vermag, einen Häretiker zu bekehren, dann ruft sie die linke Hand zu Hilfe, um die Häretiker mit Waffengewalt zu bezwingen. Und so zeigt der Herr in aller Deutlichkeit, dass es Petrus (...) erlaubt ist, Waffengewalt zu gebrauchen“"106).

Und an anderer Stelle:

„Den Satz, dass die Kirche kein materielles, sondern nur ein geistliches Schwert habe, kann man auf zweierlei Weise auffassen. Einmal in dem Sinne, dass sie es nicht hat, um es mit eigener Hand zu führen oder um Todesurteile zu verhängen; zum anderen in dem Sinne, dass sie es nicht hat, um Fürsten oder Völkern zu befehlen, die Kirche mit dem Schwert zu verteidigen oder Häretiker zu verfolgen oder die Türken in einem gerechten Krieg zu bekämpfen. Wir gestehen ein, dass die Kirche kein materielles Schwert im ersten Sinne hat (...). Was den letzten Sinn betrifft, so kann es nicht bestritten werden, dass die Kirche beide Schwerter besitzt, und dass Schwert unter Schwert steht, das materielle nämlich unter dem geistlichen, wie der heilige Bernhard lehrt in De Consideratione Buch 4, Kap. 4 und Bonifaz VIII. in Unam Sanctam“107).

Wiederholt ist Bernhard von Clairvaux die unmittelbare Grundlage für die Zwei-Schwerter-Lehre, wobei schon Stefania Tutino darauf hingewiesen hat, welche Schwierigkeiten Bellarmin die berühmte Passage aus De consideratione bereitete. In der ersten Edition von De summo Pontifice (1586) verweist er darauf, dass Bernhard in seiner mystischen Auslegung von Luk 22,38 keineswegs sagen wolle, der Papst habe beide Schwerter in derselben Weise. In der Edition von 1599 erklärt er, dass Bernhard zwar tatsächlich sage, dem

$\left.{ }^{106}\right)$ Bellarmino, De laicis, c. XXII, col. 1829: Ecclesia sicut habet Principes Ecclesiasticos, et saeculares, qui sunt quasi duo Ecclesiae brachia, ita duos habet gladios, spiritualem, et materialem, et ideo quando manus dextera gladio spirituali non potuit haereticum convertere, invocate auxilium brachii sinistri, ut gladio ferreo haereticos coerceat et hoc fortasse significavit Dominus, cum prohibuit Petrum (...) uti gladio ferreo. Vgl. D ordett (oben Anm. 102) 17. Hier wird im Grunde wieder die frühmittelalterliche ecclesia universalis bemüht, in der die Rolle des weltlichen Fürsten allein über seine religiöse Funktion definiert wird. Vgl. Murray (oben Anm. 84) 507ff.; J os eph L ecler, L’Église et la souveraineté de l’État, Paris 1946, S. 104.

${ }^{107}$ ) Auctarium Bellarminianum (oben Anm. 99) 370: Potest duobus modis intelligi Ecclesiam non habere gladium materialem, sed spiritualem. Uno modo, ut non habeat ad feriendum vel manu propria, vel sententia judicaria, quae damnat sontes ad mortem; altero modo, ut non habeat ad jubendum principibus vel populis ut gladio Ecclesiam defendant, vel haereticos persequantur, vel Turcas justo bello oppugnent. Et quidem priore modo fatemur ecclesiasticos non habere gladium materialem (...). Posteriore modo negari non potest quin ad Ecclesiam gladius uterque pertineat, et quod gladius gladio subsit, materialis videlicet spirituali, ut sanctus Bernardus docet lib. 4 de Consideratione, cap. 4, et Bonifacius VIII, cap. Unam sanctam. 
Papst würden beide Schwerter gehören, jedoch zeige das Werk des großen Zisterziensers an zahlreichen anderen Stellen, dass dem Papst nur eine geistliche und keine zeitliche Gewalt einzuräumen sei $\left.{ }^{108}\right)$. In seiner Replik auf die Kritik Barclays (1610) sieht sich Bellarmin schließlich gezwungen, der ZweiSchwerter-Auslegung durch Bernhard ein ganzes Kapitel einzuräumen, um klarzustellen, dass das utriusque gladius im Sinne der potestas indirecta zu verstehen sei ${ }^{109}$ ). Der Papst habe also beide Schwerter, aber nur eine - geistliche - Gewalt.

Bei Suarez heißt es:

„Der weltliche Fürst besitzt und gebraucht das materielle Schwert in direkter Weise, die Kirche hingegen nur indirekt und gleichsam eminent, insofern sie sich kraft ihrer Höherrangigkeit auch das materielle Schwert des Fürsten unterwirft, auf dass jener es auf ihren Wink hin im Dienste der ewigen Gerechtigkeit gebrauchen möge $^{(110)}$ ).

Das materielle Schwert symbolisiert also die potestas saecularis des Fürsten und zugleich auch die materielle Zwangsgewalt der Kirche $\left.{ }^{111}\right)$. Schon Hans Barion kritisierte jedoch zu Recht jene Varianten der potestas indirecta, die die Verfügung über die weltliche (Staats)Gewalt fallweise dem weltlichen Fürsten oder dem Papst zuschrieb, je nachdem, ob der geistliche Endzweck betroffen war.

„Die Gewalt der Kirche und die des Staates über das Weltliche sind nicht etwa nur dadurch unterschieden, daß die eine mittelbar, die andere unmittelbar wirksam wird. Staat und Kirche wären dann zwei Träger der gleichen Gewalt; die mittelbare Gewalt der Kirche wäre gleichsam eine verlängerte unmittelbare Gewalt, eine Gewalt, die sie einem Stellvertreter überläßt und gelegentlich durch ihn ausübt, die sie aber auch selbst gebrauchen kann. Diese Auslegung der mittelbaren Gewalt ist zwar nicht selten anzutreffen, scheitert aber außer an anderen Gründen daran, daß nach der schon einmal erwähnten Lehre der Kirche sie selbst sowohl wie der Staat

${ }^{108}$ ) Vgl. Tutino (oben Anm. 84) 42f. Anm. 115.

${ }^{109)}$ Bellarmino, Tractatus (oben Anm. 105) c. 19, S. 183-190.

$\left.{ }^{110}\right)$ Francisco Suarez, De fide theologica, Paris 1858, S. 519: Princeps autem temporalis directe habet materialem gladium et usum ejus; Ecclesia vero solum indirecte et quasi eminenter, ratione cujus eminentiae etiam materialem gladium principis habet sibi subordinatum, ut suo nutu, servata justitiae, illo uti possit. Vgl. Dordett (oben Anm. 102) 14.

111) Vgl. Francisco Suarez, De fide (oben Anm. 110) 517 zur Erläuterung der Zwei-Schwerter-Lehre nach Bernhard von Clairvaux: Per quae verba docet Bernardus, et approbat, Bonifacius, esse potestatem in Ecclesia etiam ad poenas, quae gladio materiali infliguntur, quamvis ipsa illas non exequatur nisi per ministerium potestatis saecularis, sicut etiam hodie fieri videmus; et hanc veritatem de subordinatione potestatis saecularis ad Ecclesiam etiam in hoc munere, tanquam necessarium ad salutem nobis proponit Pontifex in fine illius textus. 
vollkommene und jeweils für ihren Bereich höchste Gesellschaften sind (...). Auch rein juristisch betrachtet ist der Begriff der mittelbaren Gewalt in dem Sinn, daß dieselbe dem Staat unmittelbar, der Kirche mittelbar, aber beiden unabhängig voneinander zukomme, ein Unding“"112).

Freilich müssen sich Bellarmin und Suarez in ihrer Interpretation der ZweiSchwerter-Lehre mit dem Einwand auseinandersetzen, was denn passiere, wenn der weltliche Fürst sich weigert, sein Schwert in den Dienst der Kirche zu stellen. Gerade diese Situation war für Stickler ja der Ausgangspunkt seiner Überlegungen zum gladius materialis ecclesiae gewesen, und auch Vitoria hatte wie gesehen diesen Fall jenseits der von ihm ebenfalls vertretenen potestas indirecta diskutiert und dabei klar zum Ausdruck gebracht, dass der Papst in solchen Notsituationen einen eigenen, von der Staatsgewalt zu unterscheidenden gladius materialis besitze, mit dem er gleichsam wie ein König einem Volk (oder anderen katholischen Laienfürsten) die bewaffnete Verteidigung der Kirche auftragen könne. Andernfalls sei der Papst hinsichtlich des gladius materialis vom Wohlwollen des Staates abhängig und die Kirche somit keine societas perfecta. Bei Bellarmin sucht man ein derart positives Bekenntnis zu einem kircheneigenen, staatsunabhängigen gladius materialis jedoch vergebens. In seiner Replik auf Wilhelm Barclay beharrt Bellarmin zunächst - ganz im Sinne der potestas indirecta - auf dem Wirken des geistlichen Schwertes:

„Wenn der Kaiser das Schwert auf den Wink des Priesters nicht zücken will, oder wenn er es wider den Wink des Priesters zückt, und es betrifft eine geistliche Sache, dann kann der Papst sein geistliches Schwert aus der Scheide ziehen und ihn durch kirchliche Vorschriften dazu zwingen, das materielle Schwert [im Interesse der Kirche] zu schwingen oder es wieder in die Scheide zurück zu stecken“"113).

Dann freilich fährt er fort:

„Wenn er sich aber nicht durch die kirchlichen Vorschriften bewegen lässt, und es liegt der Kirche daran, dann kann der Papst die Untertanen vom Gehorsam gegenüber dem weltlichen Herrscher lossprechen, und diesen seines Reiches entsetzen. Auf diese Art kann der Papst zeigen, dass Schwert unter Schwert steht, und beide Schwerter der Kirche gehören, wiewohl nicht auf gleiche Art und Weise“"114).

$\left.{ }^{112}\right)$ Hans Barion, Kirche oder Partei? Der Katholizismus im neuen Reich, in: Europäische Revue 9 (1933) 401-409, S. 406.

${ }^{113}$ ) Bellarmino, Tractatus (oben Anm. 105) c. 19, S. 185: Si nolit imperator ad nutum sacerdotis gladium stringere, vel si contra nutum eius strinxerit, et res sit at bonum spirituale necessaria, coget illum Pontifex gladio spirituali, id est censures Ecclesiasticis, gladium materialem stringere, aut in vaginam recondere. Vgl. auch ebd. c. 2, S. 43.

$\left.{ }^{114}\right)$ Ebd. c. 19, S. 185: Si censuris non movebitur, et Ecclesiae necessitas id requirat, liberabit subditos eius ab obedientia eique imperium abrogabit. Ita ostendet 
Man mag diese Stelle noch in dem Sinne deuten, dass die geistliche Zwangsgewalt mitunter Konsequenzen im zeitlichen Bereich gleichsam indirecte nach sich ziehen kann, die bis hin zu einer de facto Absetzung des exkommunizierten weltlichen Herrschers führen ${ }^{115}$ ). An anderer Stelle jedoch hatte Bellarmin ausdrücklich ergänzt, dass der Papst in bestimmten Fällen nicht nur den weltlichen Herrscher seines Reiches entsetzen, sondern zudem die weltliche Macht an einen anderen Herrscher aktiv übertragen könne $\left.{ }^{116}\right)$. Auch wenn Bellarmin hier wiederum ausdrücklich das alleinige Wirken des geistlichen Schwertes bemüht, so legen seine Kritiker ${ }^{117}$ ) genau hier den Finger in die Wunde. Hatte Bellarmin noch eingangs seiner Verteidigungsschrift erklärt, die Subordination des weltlichen Herrschers unter den Papst rühre nicht daher, dass der Fürst seine weltliche Gewalt vom Papst verliehen bekomme - diese erhalte er qua Naturrecht von Gott und Volk -, sondern liege allein in der Höherrangigkeit des geistlichen gegenüber dem weltlichen Ziel begründet ${ }^{118}$ ), so wird nun doch im Notfall die Vergabe der weltlichen (Staats-) Gewalt durch das Wirken des geistlichen Schwertes postuliert. Während Vitoria in derartigen Notfällen auf den gladius materialis ecclesiae als eine von der Staatsgewalt verschiedene kirchlich-materielle Zwangsgewalt zurückgreift, muss Bellarmin, will er die Kirche als eine mit materieller Zwangsgewalt ausgestattete societas perfecta bewahren, aufgrund der eigentümlichen Überlagerung von Staatsgewalt und kirchlich-materieller Zwangsgewalt im System der potestas indirecta die Verleihung der naturrechtlich begründeten Staatsgewalt letztlich wieder in die Hände des Papstes legen, wodurch jegliches Beharren auf der Eigenständigkeit des Staates und die Ablehnung der Hierokratie durch Bellarmin zur leeren Formel wird ${ }^{119}$ ).

gladium esse sub gladio, et utrumque gladium ad potestatem Ecclesiae pertinere, quamvis non eodem modo.

${ }^{115}$ ) Vgl. zu dieser seit dem Investiturstreit greifbaren Vorstellung Hageneder (oben Anm. 61) 57-60, sowie Ragg (oben Anm. 8) 93ff.

${ }^{116}$ ) Bellarmino, Tractatus (oben Anm. 105) c. 5, S. 75: ... sequitur, posse Pontificem per spiritualem, atque Apostolicam eminentissimam suam potestatem dirigere, et corrigere potestatem politicam, eamque, si opus sit, ad finem spiritualem, uni Principi adimere, et alteri conferre.

${ }^{117}$ ) Die zeitgenössischen (allen voran Barclay und Roger Weddington alias Thomas Preston) wie die modernen (Henri de Lubac, Joseph Lecler, John Murray, Friedrich Kempf).

${ }^{118}$ ) Bellarmino, Tractatus (oben Anm. 105) c. 2, S. 41.

${ }^{119}$ ) Vgl. die Kritik von Kempf, Katholische Lehre (oben Anm. 32) 63. Murray (oben Anm. 84) passim, und L ecler, L’Église (oben Anm. 106) 104 sehen zu Recht das Problem, dass Bellarmin zwar einerseits den Staat als naturrechtlich begründete 
Auch Suarez weist eine Abhängigkeit des Papstes vom Wohlwollen der weltlichen Fürsten als Inhaber des gladius materialis zurück, ohne wie Vitoria einen eigenen gladius materialis ecclesiae zu postulieren, so dass auch er sich unweigerlich in Widersprüche verstrickt. War für ihn das materielle Schwert die fürstliche potestas saecularis, die zugleich auch die materielle Zwangsgewalt der Kirche verkörperte, erscheint an anderer Stelle die materielle Zwangsgewalt der Kirche als eine von Christus unmittelbar übertragene Gewalt. Die zeitliche Gewalt der Kirche, so Suarez, könne gar nicht zugleich die naturrechtlich begründete Staatsgewalt der Fürsten sein, da sich die materielle Zwangsgewalt der Kirche ja gegebenenfalls auch gegen die Fürsten selbst wenden können muss ${ }^{120}$ ). Mit anderen Worten und um im Bild zu bleiben: Kein Fürst würde sich auf Anordnung des Papstes mit seinem eigenen Schwert richten. Daher können Staatsgewalt und materielle Zwangsgewalt der Kirche schwerlich ein und derselbe gladius materialis sein ${ }^{121}$ ).

Größe anerkennt, aber letztlich doch seinen Überlegungen zur potestas indirecta vor dem Hintergrund der einen mittelalterlichen societas christiana entwickelt, die regnum und sacerdotium bzw. (kath.) Staat und Kirche in einer societas perfecta vereint, deren Haupt der Papst ist.

${ }^{120}$ ) Francisco Suarez, De fide (oben Anm. 110); vgl. Dordett (oben Anm. 102) $13 f$.

${ }^{121}$ ) Dordett (oben Anm. 102) 15 u. 23f. sieht die theoretische Lösung dieser Problematik in der Unterscheidung von Strafgewalt einerseits und Zwangsgewalt andererseits. Die materielle Strafgewalt komme der Kirche prinzipiell und unabhängig von der geschichtlichen Situation zu, während die dazugehörige materielle Zwangsgewalt „von der Hilfeleistung weltlicher Fürsten abhängig und somit ohne brachium saeculare nicht denkbar“ sei. Zwar hätten bereits Bellarmin und Suarez wiederholt darauf verwiesen, dass die Kirche in gewissen Phasen ihrer Geschichte nicht die Möglichkeit gehabt hätte, ihre zeitliche Gewalt in vollem Umfang zu gebrauchen, aber erst spätere Kirchenrechtler hätte Straf- und Zwangsgewalt entsprechend ausdifferenziert. So konstatierte Alfredo Ottaviani noch Mitte des 20. Jahrhunderts: Wenn der Staat seiner Verpflichtung zum Schutz der Kirche nicht nachkommt, dann bedeutet dies für die Kirche keinen prinzipiellen Mangel an potestas, sondern an Gelegenheit, diese potestas auch zu gebrauchen. Vgl. Dagmar Schaaf, Der kirchliche Strafanspruch, Die Begründung der kirchlichen Strafgewalt vom Ius Publicum Ecclesiasticum bis zum CIC1983, Frankfurt am Main 2007, S. 70; so auch Molitor (oben Anm. 4) 239f. Diese Überlegungen waren freilich keineswegs so neuzeitlich, wie Dordett meint, sondern finden sich wie gesehen im Grunde schon bei den mittelalterlichen Kanonisten, die mit ihren Distinktionen des materiellen Schwertes in ius gladii bzw. potestas gladii, ius executionis und actum executionis diesem Problem Rechnung tragen wollten (vgl. oben S. 12). Die Summa Reverentia sacrorum canonum (oben Anm. 61) und Heinrich von Gent, Quodlibet VI, q. 23, ed. Gordon A. Wilson u.a., Henrici de Gandavo Opera omnia 10, Louvain 1987, S. 210-222, 
Nicht unproblematisch sind auch die Aussagen von Suarez darüber, auf welcher (Rechts-)Grundlage die Bestrafung von Häretikern durch die weltlichen Fürsten erfolge. Grundsätzlich, so Suarez, geschehe die materiell-zeitliche Bestrafung von Ketzern durch die weltlichen Fürsten, jedoch nicht aufgrund ihrer eigenen zeitlichen (Staats-)Gewalt, sondern aufgrund einer ihnen von der Kirche vermittelten Gewalt ${ }^{122}$ ). Andererseits gebe es Fälle (res mixtae), in denen sowohl Staat als auch Kirche durch Häresie in Aufruhr gebracht würden, so dass der weltliche Herrscher bereits aufgrund der leges civiles eingreifen könne ${ }^{123}$ ). Ausdrücklich erklärt Suarez, dass bei der materiell-zeitlichen Verfolgung und Bestrafung von Ketzern, insbesondere wenn es sich um die Verhängung der Todesstrafe handelt, die Kirche nicht eine ihr eigene Jurisdiktion an die Fürsten delegiere, sondern dass die Fürsten in diesen Fällen ihre eigene staatliche Jurisdiktion anwenden sollen ${ }^{124}$ ), wovon freilich am Ende auch die Kirche profitieren würde. Auch bei Suarez finden sich also an einigen Stellen seines Werkes Formulierungen, die inhaltlich den Thesen Sticklers zum doppelten brachium saeculare nicht unähnlich sind und zwei verschiedene Rechtsgrundlagen der materiellen Straf- und Zwangsgewalt in kirchlich-religiösen Angelegenheiten nahelegen: die eine Gewalt von der Kir-

S. 215f. vertraten z.B. den Standpunkt: Die Potestas gladii (Strafgewalt) habe der Papst unmittelbar von Gott erhalten, die executio gladii (Zwangsgewalt) hingegen habe der Kaiser unmittelbar von Gott. Eine derartige Auseinanderlegung von potestas und executio potestatis wurde sowohl von Aegidius Romanus als auch, wenngleich freilich mit anderer Intention, von Johann Quidort als absurd kritisiert, vgl. Kosuch (oben Anm. 56) 184.

122) Francisco Suarez, De legibus, Paris 1856, III, 11, 10, S. 214: Dices: nunc possunt principes seculares haereticos punire, et alia vitia contraria religioni Christianae, ut talis est, prohibere (...). Respondeo imprimis aliqua ex his non tam per se pertenire ad secularem potestatem, quam ex concessione ecclesiasticae potestatis, et quasi per tacitam vel expressam invocationem ejus postulantis auxilium brachii secularis; et ita infra dicemus universas leges civiles quae circa materias spirituales versantur, vel non esse leges, vel habere vim suam a superiori potestate. Vgl. Canavan (oben Anm. 84) 357.

123) Francisco Suarez, De legibus (oben Anm. 122) III, 11, 10, S. 214: Deinde dicimus illa vita et peccata quae dicuntur mixti fori, eatenus puniri et cohiberi reipublicae christianae illam perturbant, et magna nocumenta illi afferunt etiam quoad suam pacem, et externam felicitatem ac conservationem: hunc enim finem semper intendit ipsa potestas quatenus talis est, licet utens illa possit perfectius operari.

$\left.{ }^{124}\right)$ Francisco Suarez, De fide (oben Anm. 110) 519f.; vgl. Dordett (oben Anm. 102) 19. Murray (oben Anm. 84) 505f. findet nicht ganz zu Unrecht, dass auch Bellarmin sich um eine Antwort drückt auf die Frage, inwieweit und auf welcher (Rechts-)Grundlage die weltliche Gewalt als Instrument der Kirche (brachium saeculare) zu sehen ist. 
che an die Fürsten delegiert (die diese als minister ecclesiae ausüben), die andere den Fürsten per se immanent. Dieses gleichsam doppelte brachium saculare kann sich jedoch nicht in der von Suarez wiederholt verwendeten Zwei-Schwerter-Allegorie adäquat widerspiegeln.

Die Lehre der potestas indirecta blieb im kirchlichen Gewaltenverständnis bis ins 20. Jahrhundert hinein wirkmächtig, wenngleich natürlich eine rege und kontroverse Diskussion um das kirchliche ius gladii zu verzeichnen ist ${ }^{125}$ ). Fester Bestandteil dieser Diskussion war auch weiterhin die Zwei-SchwerterLehre, die trotz aller Kritik an ihr in der Kanonistik präsent blieb und noch in den kirchenrechtlichen Lehrbüchern von Alfredo Ottaviani, Pietro Gasparri und Franciscus Marchesi sowohl als Allegorie für die geistliche und materielle Zwangsgewalt der Kirche diente, als auch für das rechtliche Verhältnis von Staat und Kirche, welches den Staat dazu verpflichtete, der Kirche mit seiner (staatlichen) Jurisdiktion als brachium saeculare zu dienen ${ }^{126}$ ). Unter

${ }^{125)}$ Vgl. Francesco M. Marchesi, Summula iuris publici ecclesiastici, Neapoli 1960, S. 90ff. Zu den unterschiedlichen Varianten vgl. immer noch Ferdinand J. Moulart, Kirche und Staat oder die beiden Gewalten, Ihr Ursprung, ihre Beziehungen, ihre Rechte und ihre Grenzen, Mainz 1881, S. $186 \mathrm{ff}$.

$\left.{ }^{126}\right)$ Alfredo Ottaviani, Institutiones iuris publici ecclesiastici, Bd. 1 Ecclesiae constitutio socialis et potestas, 4. Aufl. Città del Vaticano 1959, Nr. 184, S. 302: Ecclesiae non competit habere immediate vim armatam: remanet ergo ut pro exsecutione suarum legum et pro punitione transgressionum vis armata ei praebeatur a Statu, qui sane ad id tenetur ob relationem quae intercedit inter ecclesiasticam et civilem societatem. Ebd. S. 303: Hinc communis fuit in Medio Aevo, etiam apud Ecclesiae Doctores et Pontifices, usus analogiae de duobus gladiis: scilicet, in gladiis de quibus sermo est in Evangelio (Luc., XXII, 38) dixerunt figuratam duplicem potestatem coercitivam Ecclesiae, alteram per poenas spirituales ab Ecclesia immediate exercendam, alteram vero, per vim physicam, ministerio principum civilum inferendam [Sperrung A.K.]. Vgl. Schaaf (oben Anm. 121) 86f.; Marchesi (oben Anm. 125) 90: ... pro executione legum Ecclesiae, Status tenetur vim armatam eidem praestare. Nam: (...) Status est ei indirecte subordinatus et proinde ei in necessitate opitulari debet (...). Sic docet Bonif. VIII in Bulla Unam Sanctam. ,Uterque gladius est in potestate Ecclesiae, spiritualis scilicet gladius et materialis. Sed is quidem pro Ecclesia, ille vero ab Ecclesia exercendus. Ille sacerdotis, is manu regum et militum, sed ad nutum et patientiam sacerdotis'; Pietro Gasparri, Institutiones iuris publici, Milano 1992, S. 249: Haec [sc. Verhängung und Durchsetzung der Todesstrafe durch die Kirche vermittels des Staats als brachium saeculare] confirmantur ex Bulla Unam Sanctam Bonifacii VIII, (...) quae Bulla dogmatica est. In ea Bonifacius VIII post D. Bernardum loquitur de duplici gladio, spirituali et temporali, qui repraesentat vim armatam Status, et ait utrumque gladium esse in potestate Ecclesiae. (...) Etiam pro applicatione aliarum poenarum temporalium seu exequutione sententiarum, Ecclesia indiget vi armata. Non est absurdum ut Ecclesiae 
dem Begriff des gladius materialis wurde letztlich sowohl die Staatsgewalt als auch die übergeordnete, auf Christus basierende materielle Zwangsgewalt der Kirche subsumiert. Eine derartige Interpretation verstärkte natürlich den Eindruck, die potestas indirecta sei nur ein Etikettenschwindel, mit dessen Hilfe auf Umwegen die Souveränität des Staates wie bei der potestas directa untergraben werden sollte ${ }^{127}$ ). Insbesondere die Zwei-Schwerter-Lehre blieb in der Auslegung der potestas indirecta unter Verweis auf die Bulle Unam Sanctam bis ins 20. Jahrhundert ein derartiger Quell für Missverständnisse, der den eigentlichen Kern der potestas indirecta - die ausschließlich geistliche Gewalt der Kirche - verdunkelte, und die ohnehin schon komplizierte innere Logik dieser Lehre unnötig belastete ${ }^{128}$ ). Die Frage nach dem Gewal-

tribunal habeat suos lictores. (...) At si tribunal ecclesiasticum illos non habeat, aut in casu aliquo particulari illi non sufficant, Ecclesia potest requirere, et Status debet manum militarem praebere [Sperrung A.K.]. Vgl. dazu Stickler, Schwerterbegriff (oben Anm. 7) 240, der die Verwendung des gladius materialis bei Ottaviani als Zeichen einer jahrhundertewährenden kanonistischen Tradition des von ihm bereits in den Quellen des 12. Jahrhunderts nachgewiesenen rein kirchlich-zwangsrechtlichen Schwerterbegriff wertet.

${ }^{127}$ ) Vgl. die Kritik Barions (Anm. 112), sowie Murray (oben Anm. 84) 501ff.; Lecler, L’Église (oben Anm. 106) 104 und Kempf , Katholische Lehre (oben Anm. 32) 63. Zur intensiven Debatte nach dem 1. Vaticanum vgl. Moulart (oben Anm. 125) 183-186; Berchtold (oben Anm. 71) 47f. Nach Ansicht von Wilhelm Martens, Das Vaticanum und Bonifaz VIII., Eine Auseinandersetzung mit Herrn Professor Berchtold, München 1888, S. 32ff. versuchten die Vertreter der potestas indirecta mit ihrer Anerkennung einer gewissen staatlichen Eigenständigkeit „dem modernen Bewußtsein einige Konzessionen [zu] machen“, um letztlich aber doch am hierokratischen System festzuhalten. Gerade jene Konzessionen würden aber durch „allerlei Beschönigungen und Abschwächungen (...) den Unkundigen irre führen.“

${ }^{128}$ ) Vgl. etwa die Konfusion hinsichtlich Schwerter-Lehre und potestas indirecta bei Otto Gierke, Das deutsche Genossenschaftrecht, Bd. 3 Berlin 1881, S. $522 \mathrm{f}$. Anm. 13; dazu auch Dordett (oben Anm. 102) 17f. Das Problem der relativen staatlichen Eigenständigkeit ist im Grunde schon bei der Interpretation der Schriften des Thomas von Aquin greifbar, der vielen Gelehrten mit seiner an Aristoteles ausgerichteten Hierarchie der Zwecke als Wegbereiter der Lehre von der potestas indirecta gilt, vgl. Lecler, L’Église (oben Anm. 106) 97ff. So ist die politische Philosophie des Aquinaten nach Ansicht von Kurt Flasch, Einführung in die Philosophie des Mittelalters, Darmstadt 1987, S. 139f. gekennzeichnet von „widerstrebende[n] Motive[n]“, die ein zwiespältiges Gesamtbild hinterlassen: Einerseits die eigenständige, d. h. kirchenunabhängige naturrechtliche Begründung der staatlichen Gewalt und ihres Daseinszwecks, andererseits die „papalistische Instrumentalisierung aller weltlichen Politik“. Diese Ambivalenz lässt sich bei Thomas mit seinem am Ende eben doch noch fest in hochmittelalterlichen Ordnungsvorstellungen verankerten Denken erklären, wonach regnum und sacerdotium als politisch-soziale Einheit verstanden werden, 
tenverhältnis hatte im Grunde schon seit dem frühen 13. Jahrhundert einen Grad an Komplexität erreicht, der diese einfache Allegorie und ihre Begrifflichkeit hoffnungslos überforderte, so dass sie allenfalls - wie Arno Borst bereits mit Blick auf ihre Verwendung durch Papst Innozenz III. prägnant konstatierte - für politische Parolen, nicht aber für eine klare herrschaftstheoretische Doktrin taugte ${ }^{129}$ ).

so dass ihm letztlich „Vorstellungen wie die, daß sich Staat und Kirche als zwei unabhängige societates perfectae gegenüberstehen (...) fremd“ waren. Vgl. Eberhard Schockenhoff, Dient die Politik dem Glück des Menschen? Zum Verhältnis von geistlicher und weltlicher Gewalt bei Thomas von Aquin, in: Theologie und Philosophie 76 (2001) 338-367, S. 342. Auch bei Bellarmin zeigt sich dieser Ansatz noch, vgl. Anm. 106. Dazu auch Moulart (oben Anm. 125) 182. Zum Problem der Christianitas als hoch- und spätmittelalterliche Ordnungskonfiguration vgl. Friedrich Kempf, Das Problem der Christianitas im 12. und 13. Jahrhundert, in: Historisches Jahrbuch 79 (1960) 104-123. Im Kern sind diese hochmittelalterlichen Ordnungsvorstellungen, die dem Staat eben nur eine relative Eigenständigkeit zugestehen, bei den traditionalistischen Anhängern der potestas indirecta bis heute die Grundlage ihres Gewaltenverständnisses geblieben, vgl. Matthias Gaudron, Die Religionsfreiheit, Das wahre Verhältnis von Kirche und Staat, in: Civitas - Zeitschrift für das christliche Gemeinwesen (2011) 1-19, S. 2. Eine Verbindung der beiden unterschiedenen, aber eben nicht getrennten societates perfectae besteht ihnen zufolge in der Pflicht des katholischen Staats, mit seiner zeitlichen Gewalt als brachium saeculare der Kirche zu dienen. Symbol für diese Pflicht war bis zuletzt die Zwei-Schwerter-Lehre und der Anspruch der Kirche auf den Besitz beider Schwerter; herrschaftstheoretischer und theologischer Hintergrund war die Lehre der Hierarchie der Zwecke, mit deren Hilfe die Superiorität des kirchlich-geistlichen Ziels gegenüber dem weltlichen Staatsziel postuliert wurde. Diese Übertragung von moralischen Prinzipien und theologischen Wahrheiten auf das Gebiet des Staatsrechts - vgl. dazu Böckenförde, Religionsfreiheit (oben Anm. 2) 49f. und Rhon heimer, Christentum (oben Anm. 38) 84f. - wurde letztlich erst durch die in Dignitatis humanae vollzogene klare Unterscheidung zwischen moralischer und juridischer Ordnung aufgegeben, wodurch der kirchliche Anspruch auf ein brachium saeculare und den gladius materialis endgültig hinfällig wurde.

${ }^{129}$ ) Borst (oben Anm. 76) 40. 